bioRxiv preprint doi: https://doi.org/10.1101/2020.06.03.132316; this version posted March 3,2021 . The copyright holder for this preprint

(which was not certified by peer review) is the author/funder, who has granted bioRxiv a license to display the preprint in perpetuity. It is made available under aCC-BY-NC-ND 4.0 International license.

\title{
Schizosaccharomyces pombe KAT5 contributes to resection and repair of a DNA double strand
} break

\author{
Tingting $\mathrm{Li}^{1}$, Ruben C. Petreaca ${ }^{1 \& 2}$ and Susan L. Forsburg ${ }^{1 \& *}$
}

${ }^{1}$ Program of Molecular and Computational Biology, University of Southern California, Los Angeles

CA $90089-2910$

${ }^{2}$ Department of Molecular Genetics, Ohio State University, Marion OH 43302

*Corresponding author at Forsburg@usc.edu

Keywords: fission yeast, DSB repair, KAT5, Mst1, resection

\section{Abstract}

Chromatin remodeling is essential for effective repair of a DNA double strand break. KAT5 (S. pombe Mst1, human TIP60) is a MYST family histone acetyltransferase conserved from yeast to humans that coordinates various DNA damage response activities at a DNA double strand break (DSB), including histone remodeling and activation of the DNA damage checkpoint. In $S$. pombe, mutations in $m s t 1^{+}$causes sensitivity to DNA damaging drugs. Here we show that Mst1 is recruited to DSBs. Mutation of $m s t 1^{+}$disrupts recruitment of repair proteins and delays resection. These defects are partially rescued by deletion of $p k u 70$, which has been previously shown to antagonize repair by homologous recombination. These phenotypes of $m s t 1$ are similar to pht1-4KR, a non-acetylatable form of histone variant H2A.Z, which has been proposed to affect resection. Our data suggest that Mst1 functions to direct repair of DSBs towards homologous recombination pathways by modulating resection at the double strand break.

\section{Introduction}

The DNA damage response choreographs multiple cellular activities such as lesion detection, activation of the DNA damage checkpoint, break repair, and recovery (rev. in (Langerak and Russell 2011)). Chromatin remodeling is central to the faithful execution of these processes, requiring the coordination of histone modifiers, remodelers, and chromatin assembly factors (rev. in (Bakkenist and Kastan 2015; Clouaire and Legube 2019; Aleksandrov et al. 2020)). Acetylation of histone H4 is one marker associated with chromatin remodeling at a double strand break (DSB), a potentially lethal form of DNA damage. There is good evidence that histone $\mathrm{H} 4$ acetylation is linked to radioresistance and the repair response, possibly by facilitating chromatin mobilization (rev. in (Dhar et al. 2017; Van and Santos 2018)).

The MYST family of histone acetyltransferases (HATs) is defined by a distinct catalytic domain, and its members are implicated in histone acetylation at DSBs (rev. in (Utley and Côté 2003; Thomas and Voss 2007)). KAT5 is the most highly conserved HAT of this family, known as Mst1 in $S$. pombe, Esa1 in $S$. 
cerevisiae, and TIP60 in mammals (rev. in (Avvakumov and Côté 2007; Pillus 2008)). The gene is essential for viability in all species, because in addition to its role in DSB repair it performs other functions such as transcriptional regulation, heterochromatin assembly and centromere assembly (rev. in (Pillus 2008)). In humans, TIP60 has also been identified as a tumor suppressor (rev. in (Sapountzi et al. 2006; Voss and Thomas 2009) and is a therapeutic target (rev. in (Judes et al. 2015)).

KAT5 contains a chromodomain in addition to its HAT domain, which suggests that it binds methylated histones (rev. in (Utley and Côté 2003; De La Cruz et al. 2005)). KAT5 functions in the context of a large protein complex called $\mathrm{NuA} 4$, and acetylates numerous substrates including histones $\mathrm{H} 2 \mathrm{~A}, \mathrm{H} 3$, and $\mathrm{H} 4$, and the histone variants H2A.X and H2A.Z (Kimura and Horikoshi 1998; Smith et al. 1998; Allard et al. 1999; Galarneau et al. 2000; Babiarz et al. 2006; Keogh et al. 2006). Evidence from human cells has shown that KAT5 can acetylate non-histone proteins as well, including the checkpoint kinase ATM and the tumor suppressor TP53 (Sun et al. 2005; Jiang et al. 2006; Leduc et al. 2006; Sykes et al. 2006; Tang et al. 2006; Kim et al. 2007; Naidu et al. 2012; Ortega-Atienza et al. 2016). Importantly, NuA4 cooperates with the Swr1 chromatin remodeler that is required for exchange of histone H2A with the variant H2A.Z ((rev. in (Scacchetti and Becker 2021) (Kobor et al. 2004; Krogan et al. 2004; Keogh et al. 2006; Zhou et al. 2010)).

Evidence from both yeast and humans shows that the NuA4 complex is recruited to DSBs by multiple binding partners including phosphorylated H2A(X) (Downs et al. 2004), methylated histone H4K20 (Jacquet et al. 2016), methylated histone H3K36 (Li and Wang 2017), methylated histone H3K9 via the KAT5 chromodomain (Sun et al. 2005; Sun et al. 2009, Ayrapetov et al. 2014), and interaction with Nbs1, a component of the end-binding resection complex MRN (Cheng et al. 2018). In fission yeast, physical association between KAT5/SpMst1 and the homologous recombination protein Rad52 has also been demonstrated (Gómez et al. 2008). However, how these recruiting partners cooperate or compete with each other is unknown.

Recruitment of the NuA4 complex to the sites of DSBs has several outcomes. There is evidence that the recruitment of variant H2A.Z and its subsequent acetylation by KAT5 are an essential early step in the DNA damage response (Morillo-huesca et al. 2010; Papamichos-Chronakis et al. 2011; Xu et al. 2012; Gursoy-Yuzugullu et al. 2015). H2A.Z must be acetylated and then removed so that KAT5 can acetylate H4 (Bird et al. 2002; Downs et al. 2004; Doyon et al. 2004; Murr et al. 2005; Clarke et al. 2017). Acetylation of the damage specific phosophorylated histone variant $\gamma-\mathrm{H} 2 \mathrm{~A}(\mathrm{X})$ promotes its turnover (Ikura et al. 2007; Jha et al. 2008; Sharma et al. 2010; Soria et al. 2012). There is also evidence that NuA4 acetylates the ssDNA binding protein RPA, to regulate resection (Cheng et al. 2018; Kobayashi et al. 2010; Xu et al. 2010). This activity may be important to activate the homologous recombination pathway as opposed to other types of repair (Renaud et al. 2015; Jacquet et al. 2016). 
In fission yeast, Mst1 has multiple activities in chromosome structure, heterochromatin assembly, centromere function, and transcription (Minoda et al. 2005; Gómez et al. 2008; Kim et al. 2009; Nugent et al. 2010; Xhemalce and Kouzarides 2010). Previously, we showed that the temperature sensitive mutation $m s t 1^{\text {ts }}$ (mst1 $n m t: m s t 1-L 344 S)$ results in sensitivity to DNA damaging agents even at permissive temperatures (Gómez et al. 2008; Gómez, Espinosa, and Forsburg 2005). Although we showed that $m s t 1^{+}$affects transcription of a variety of genes, changes in expression do not appear sufficient to account for its DNA damage sensitivity (Nugent et al. 2010). Here, we present evidence that $m s t 1^{+}$affects DSB repair in fission yeast. We show that Mst1 is recruited to DSB. mst1-L344S cells show defects in recruiting downstream factors including Rad52 and RPA. Interestingly, this phenotype is partially rescued by deletion of the end-binding protein Pku70, normally required for NHEJ repair. Our data suggest that Mst1 contributes to efficient resection. Finally, a non-acetylatable H2A.Z mutant (pht1-4KR) phenocopies mst1-L344S, indicating that H2A.Z may be an important substrate for this effect.

\section{Materials and methods}

\section{Strains and Media}

Fission yeast cells were grown in YES (yeast extract with supplements) or PMG (pombe minimal glutamate) with appropriate supplements (Sabatinos and Forsburg 2010). Yeast strains used in this research are listed in Supplementary table S2 in the supplemental material.

\section{Serial Dilution plating}

Yeast cell cultures were grown at $25^{\circ} \mathrm{C}$ in YES for two days. Cultures were diluted in YES to equal concentrations. Five-fold serial dilutions of the cultures were then spotted onto YES plates containing different concentrations of drugs. Plates were incubated at $25^{\circ} \mathrm{C}$ or $32^{\circ} \mathrm{C}$ for the time indicated in each figure legend.

\section{Determination of DSB-induced recombination rates}

DSB-induced recombination outcomes were determined using the strain ade6-M26 int::pUC8/ura4+/MATa/ade6-L469 described in (Schuchert and Kohli 1988; Fortunato et al. 1996). The $S$. cerevisiae homothallic endonuclease $(\mathrm{HO})$ was expressed on a plasmid from the $n m t 1$ promoter. Cells were first grown up in PMG (pombe minimal glutamate) liquid media lacking uracil and thiamine (PMG -ura -thia) for two days. Cell cultures were then plated onto PMG -ura -leu thia agar media for five days at $25^{\circ} \mathrm{C}$. After the five-day incubation, colonies were then streaked onto PMG -leu -thia agar media and incubated at $25^{\circ} \mathrm{C}$ for seven days (HO expression induced). Three colonies from each induced-break plate were then selected and serially diluted 1:100 in sterile MilliQ H2O. 100 $\mu$ l of the diluted cultures was plated onto PMG low ade -leu thia agar media. Agar plates were incubated at $25^{\circ} \mathrm{C}$. After the 14 -day incubation, red, white and red/white half sectored colonies were counted and marked. Plates were then replica plated onto PMG -leu -ade -thia and PMG 
100 -ade, -ura -thia and allowed to grow for another six days at $25^{\circ} \mathrm{C}$ before counting colonies with each phenotype.

101 At least three biological replicates were performed. About 8\% are likely "complex" rearrangement, for 102 example colonies that were red/white half sectored on PMG low ade -leu -thia agar media. These colonies arise 103 from recombination intermediates that were not repaired before replication (Fortunato et al. 1996).

\section{Live-cell imaging and Quantitative Measurements}

105 Live cells imaging was performed as described in (Green et al. 2015). Yeast cell cultures were grown 106 at $25^{\circ} \mathrm{C}$ in YES overnight. Cells were transferred into PMG + HULAA (Histidine, Uracil, Leucine, Adenine, 107 Arginine) liquid cultures at $25^{\circ} \mathrm{C}$ for 16 hours before treating with the indicated drugs for four hours. Cells 108 were collected at $\mathrm{OD}_{595} 0.3-0.6$, concentrated by centrifuging $1 \mathrm{ml}$ at $1500 \mathrm{~g}$ for $1 \mathrm{~min}$ and resuspended in $40 \mu 1$. 109 Concentrated cells were placed on a thin-film pad of $2 \%$ agarose in PMG+HULAA on a glass slide. A coverslip 110 was added. Live cells were imaged on DeltaVision Core microscope with softWoRx v4.1 (GE, Issaquah, WA), 111 using a 60X lens, and then deconvolved and projected in softWoRx software. Images were acquired in 13 $1120.2 \mu \mathrm{m}$ z-sections, then deconvolved and Maximum Intensity Projected (softWoRx, default settings). Two 113 separate fields were imaged in each experiment, and 2 to 4 biological replicates were assessed for consistency. 114 Images for publication were contrast adjusted using an equivalent histogram stretch on all samples. Color 115 balance was adjusted, and scale bars were added in Fiji (Schindelin et al. 2012). Significance was calculated 116 using the Mann-Whitney U test.

\section{LacO LacI-mCherry DSB array colocalization with CFP-tagged Rad52}

118 Co-localization was performed as described in ( $\mathrm{Yu}$ et al. 2013). Cells were cultured at $25^{\circ} \mathrm{C}$ in $\mathrm{PMG}+$ 119 HULAA (Histidine, Uracil, Leucine, Adenine, Arginine) +Thiamine liquid media to OD595 of 0.4-0.6. Cells 120 were then washed twice with PMG +HULAA medium and incubated at $25^{\circ} \mathrm{C}$ for 19 hours to induce HO-driven

121 DSB break. Following induction, cells were collected at $\mathrm{OD}_{595}$ of 0.3 to 0.6 , and were processed and imaged 122 as described above.

\section{Chromatin Immunoprecipitation (ChIP) assay}

124 Chromatin immunoprecipitation (ChIP) was performed as in (Du et al. 2006). Cells were grown in 125 PMG+HULAA+Thiamine overnight to $\mathrm{OD}_{595} \sim 0.6$. Cells were washed 3 times with EMM+HULAA and 126 released in PMG+HULAA-Thiamine at $32^{\circ} \mathrm{C}$ with shaking. Samples were taken after washing into 127 PMG+HULAA-Thiamine $(\mathrm{T}=0), 22 \mathrm{hrs}(\mathrm{T}=22), 24 \mathrm{hrs}(\mathrm{T}=24)$ and $26 \mathrm{hrs}(\mathrm{T}=26)$. All samples were fixed with $1281 \%$ formaldehyde for $20 \mathrm{~min}$ followed by 5 minutes quenching with Glycine. Cells were lysed in standard ChIP 129 buffer and immunoprecipitations were set up using antibodies against GFP (Abcam290), V5(Abcam15828). 130 DNA was column purified using a Qiagen PCR purification kit and qPCR was performed. Fold enrichment 131 was calculated as $100 * 2 \wedge($ Adjusted $100 \%$ INPUT $-\mathrm{Ct}(\mathrm{IP}))$.

\section{Western Blots}


For the time course experiment, cells were grown at $32^{\circ} \mathrm{C}$ in YES to $\mathrm{OD}_{595} \sim 0.6$ then treated with $40 \mu \mathrm{M}$

134 camptothecin (CPT) for 4hrs. Cells were washed three times with YES, then released in YES without drug.

135 Time points were taken at $\mathrm{T}=0$ (before addition of drug), $\mathrm{T}=4$ (after $4 \mathrm{hrs}$ of drug treatment), and $\mathrm{T}=6,8$ (two

136 and four hours after removal of drug). Cells were lysed in 20\% TCA. Antibodies against phosphorylated H2A

137 (Abcam 17353) and control PCNA (Santa Cruz-56 PC10) were used. For the Chk1-HA phosphorylation

138 experiment, cells were grown at $32^{\circ} \mathrm{C}$ in YES to $\mathrm{OD}_{595} \sim 0.6$ then treated for $4 \mathrm{hrs}$ with $40 \mu \mathrm{M}$ camptothecin,

$13915 \mathrm{mM}$ HU or $0.01 \% \mathrm{MMS}$ then cells were processed as described above. An anti-HA antibody (12CA5

140 Abcam16918) was used.

\section{Reagent, software, and data availability}

142 All strains and other reagents are available to other investigators upon request. All data are provided 143 within the figures and manuscript or in Supplemental Data uploaded to the GSA Figshare portal. Fig S1: mst 1$144 L 344 S$ sensitivity to phleomycin. S2: Examples of repair protein focus formation in wild type and mutants. S3: 145 pku70 does not affect cell length. S4: Genetic interactions between mst1-L344S and checkpoint mutants. 146 Table S1: Median and quantiles of data in Fig 2A and B. S2: Strain list.

149 Mst1 is important for double-strand break repair in S. pombe

Mst1 homologs in mammalian cells (TIP60) and S. cerevisiae (ESA1) are known to be important for 151 DSB repair (rev. in (Ghobashi and Kamel 2018; Van and Santos 2018; Clouaire and Legube 2019; Aleksandrov 152 et al. 2020)). We have previously shown that a S. pombe $m s t 1^{+}$temperature sensitive allele (mstl-L344S) 153 renders cells sensitive to various DNA damaging drugs (Gómez et al. 2008). Here we expand these studies to 154 further dissect the role of $m s t 1^{+}$in DSB repair.

155 Our original $m s t 1-L 344 S$ construct is expressed from the $n m t 1$ promoter inserted at the leu $1^{+}$locus in 156 a deletion background (mst1 nmt:mst1-L344S Gómez et al. 2008) but subsequently, the same allele was 157 engineered at the native locus under control of the endogenous $m s t 1^{+}$promoter (mstl-L344S Garabedian et al. 158 2012). We tested the sensitivity of both versions to bleomycin, which creates single and double strand DNA 159 breaks (Stubbe and Kozarich 1987; Burger 1998). Both these strains were modestly sensitive to the drugs at $16025^{\circ} \mathrm{C}$ (Figure 1A; Gómez et al. 2008), consistent with a requirement for Mst1 in DSB repair. Because the mst 1$161 L 344 S$ allele does not generate autofluorescence to the same extent as our original allele, we employed it here 162 for visual assays.

163 We investigated the role of $m s t 1^{+}$in repair of a single DSB break. We first utilized a strain that uses 164 the homothallic switching endonuclease (HO) to induce a single DSB between two non-tandem repeats as 165 originally described by (Schuchert and Kohli 1988) and modified by (Osman et al. 2000) (Figure 1B). In this 
166 strain, a functional $\mathrm{ura}^{+}$gene is flanked by two full length non-functional ade6 alleles, each containing a 167 different point mutation. The HO endonuclease makes a DSB at MATa site adjacent to ura4 ${ }^{+}$. The repair 168 outcomes can be determined by selecting $\mathrm{Ade}^{+}$cells and screening for $\mathrm{Ura}^{+}$(Fortunato et al. 1996; Osman et 169 al. 1996, 2000; Ahn et al. 2005). Uracil auxotrophic colonies ("deletion type", whether Ade ${ }^{+}$or Ade') result 170 from deletion and rearrangement, in which cells repaired the lesion by $\underline{\text { Single }} \underline{\text { Strand }}$ Annealing (SSA), №n171 Homologous End-Joining (NHEJ), or more complex rearrangements. In contrast, Ade ${ }^{+}$colonies that retain 172 Ura+ ("conversion type") are presumed to derive from gene conversion via homologous recombination.

Following induction of the DSB, we observed that the survival of mst $1-L 344 S$ was much lower than 174 the survival in wild-type cells (Figure 1C), consistent with a repair defect. In wild-type cells, about 55.64\% of 175 colonies are deletion type (Ade+/Ade- Ura-) while 36.70\% of colonies were conversion type (Ade+ Ura + ) 176 (Figure 1D). In the surviving mst1-L344S cells, we observed a significantly higher percentage of colonies 177 showing deletion-type repair (75.3\%) than in wild type (Figure 1D). These data suggest that wild type $m s t 1^{+}$ 178 biases repair towards conversion-type, error-free recombination.

To examine whether Mst1 physically localizes to DSB breaks as has been reported for HsTIP60 and 180 ScEsa1 (Downs and Jackson 2004; Sun et al. 2009), we employed a strain previously engineered to test recruitment of proteins by ChIP to one single double strand break (Figure 1E) (Du et al. 2006). This assay can monitor both temporal and spatial recruitment of proteins to a single DSB. We detected Mst1 localized near the DSB after induction, although the level of enrichment was lower than that of Rad52 (Figure 1E, note two different Y-axes for Mst1 and Rad52). As expected, Mst1 localization to sequences near DSB was reduced in cells missing H3K9 methyltransferase Clr4 (Figure 1E), which is consistent with previous finding that HsTIP60 binds to the DSB via H3K9 ${ }^{\text {me }}$ (Sun et al. 2005; Sun et al. 2009, Ayrapetov et al. 2014). Additionally, Rad52 localization to the DSB was reduced in $c l r 4 \Delta$ (Figure 1E and F), consistent with findings in human cells that $\mathrm{H} 3 \mathrm{~K} 9^{\text {me }}$-deficient cells had reduced homologous recombination-mediated repair (Ayrapetov et al. 2014, Sun et al. 2009).

\section{Mst1 contributes to recruitment of repair factors to DSBs}

Consistent with a role for Mst1 in DSB repair, we found that the mutant $m s t 1$ at permissive temperature is modestly sensitive to agents that induce DSBs, including the radiomimetic drugs Bleomycin and its analogue

193 Phleomycin (Belenguer et al. 1995) (Figure 1A, supplementary figure 1), suggesting this mutant has attenuated

194 function even under permissive conditions. We next examined the recruitment of homologous recombination 195 proteins in mst1-L344S cells using a visual screen following treatment with phleomycin. First, we looked at 196 the localization of RPA and Rad52 proteins (Figure 2A, supplementary table 1). Untreated wild type and $m s t 1$ 197 cells had a similar percentage of cells with foci. However, following phleomycin treatment, we observed 198 significantly more cells with foci in wild type than in mst1-L344S cells. We also imaged cells with GFP-tagged 
199 Rad54, a recombination protein that acts downstream of Rad52 (Figure 2B; Onaka et al. 2016). Similar to RPA 200 and Rad52, the fraction of $m s t 1-L 344 S$ cells with Rad54 foci was lower than in the wild type strain (Figure 2B, 201 supplementary table 1). These observations suggest that Mst1 is required for the normal recruitment of 202 downstream HR factors.

Next, we examined the recruitment of Rad52 at a single, induced DSB site. We utilized a strain that 204 contains an HO-inducible DSB adjacent to a lacO array that recruits mCherry-lacI, and CFP-tagged Rad52 205 (Yu et al. 2013). We imaged both wild-type and mst1-L344S cells over a four-hour period. In wild-type cells, 206 we observed that $75 \%$ of total Rad52 foci co-localize with mCherry signal until 100 minutes (Figure 2C top). 207 After 100 minutes, the percentage of colocalization dropped in wild type, because the mCherry-LacI signal 208 disappears (Figure 2C bottom and Figure 2D). This loss of mCherry-lacI likely reflects resection at DSBs that 209 eliminates the LacO target, as shown previously (Yu et al. 2013; Leland et al. 2018). Consistent with these 210 prior reports, we observed that the mCherry-DSB foci dropped to $25 \%$ by the end of four-hour time-course 211 (Figure 2D, Yu et al. 2013). In contrast, in mst1-L344S cells, fewer than 40\% of total Rad52 foci colocalize 212 with mCherry-DSB foci across the four-hour time-course, suggesting Mst1 is involved in Rad52 recruitment 213 (Figure 2C top). Strikingly, however, over 90\% of mCherry-DSB signal remained even at the end of the time214 course (Figure 2C bottom and Figure 2D). This suggests that in the absence of functional Mst1, resection is 215 inhibited, so the LacI-mcherry bound to the lacO array persists.

\section{Processing of DSBs and a role for Ku}

The heterodimeric Ku complex is very abundant and binds rapidly and immediately to DSBs (Fell and Schild-Poulter 2015; Shibata et al. 2018). Ku inhibits initial resection driven by MRN, while MRN removes $\mathrm{Ku}$ to promote proper resection and facilitate homologous recombination (HR) (Tomita et al. 2003; Langerak et al. 2011; Shao et al. 2012; Myler et al. 2017; Shibata et al. 2018). Unexpectedly, we found that pku70 partially rescues the bleomycin sensitivity of mst1 $m s t 1-L 344 S$ (Figure 3A).

We wondered whether Pku70 also affects the recruitment of repair proteins in $m s t 1-L 344 S$, so we imaged fluorescently tagged RPA under phleomycin treatment. We observed first that the percentage of

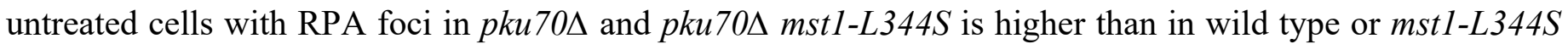
(Figure 2A, supplementary figure 2, supplementary table 1), suggesting a burden of endogenous damage. 226 However, cell growth and cell length at septation were not significantly affected (Figure 3A, supplementary 227 figure 3).

Upon treatment, the number of positive cells is only slight increased, and does not reach the level 
230 different for Rad52: the pku70s single mutant cells showed a comparable level to wild type in untreated

231 conditions, with little change following treatment. The untreated double mutant pku70 mst1-L344S were

232 higher than either single mutant and showed a modest increase upon treatment, but not to the levels of wild

233 type (Figure 2A, supplementary figure 2A, supplementary table 1). Finally, the fraction of pku70 4 with Rad54

234 foci is similar to wild type in untreated cells, increased by the same relative proportion following treatment.

235 Again, the untreated mst1-L344S pku70د has a higher baseline in untreated cells than either single mutant, and

236 induces to approximately wild type levels (Figure 2B, supplementary figure 2C, supplementary table 1).

We used the mCherry-LacI marked HO-induced DSB system to examine the apparent resection of DSB 238 in pku70 mutants by monitoring the disappearance of mCherry signal (Figure 2D). We find that $p k u 70 \Delta$ 239 single mutant cells do show a slight reduction in mCherry-DSB foci over time, but this effect is far more 240 modest than that in wild-type. At the end of the time-course, just under $70 \%$ of the $p k u 70 \Delta$ cells still contain

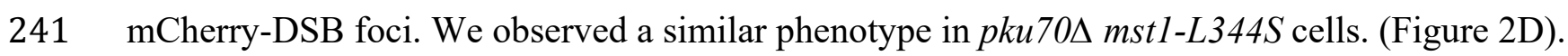

Long range resection is initiated by MRN and extended by the exonuclease Exo1, as well as other proteins (Zhu et al. 2008; Langerak et al. 2011; Yan et al. 2019). We observed that mCherry-LacI marked

244 DSBs do not disappear over the time-course in exo1 $\Delta$, in contrast to wild-type (Figure 2D), and consistent with 245 a failure in resection. We observed that exo1 $\Delta$, mst1-L344S, and the double mutant exo1 $\Delta$ mst $1-L 344 S$ all show 246 a similar persistence of the mCherry signal. Additionally, exols mst1-L344S has similar sensitivity to 247 bleomycin as the mst $1-L 344 S$ single mutant and this sensitivity is rescued by pku70 (Figure 3A). These data 248 suggest that $\mathrm{mstl}^{+}$and $\mathrm{exol}^{+}$are in the same pathway.

\section{Is H2A.Z a target of Mst1 to regulate DSB repair?}

In other organisms that the presence and turnover of the histone variant H2A.Z (S. pombe Pht1), a KAT5 substrate, is important for the proper repair of DSBs by regulating resection (Xu et al. 2012; GursoyYuzugullu et al. 2015; Jiang et al. 2015). In human cells, H2A.Z depletion leads to higher ssDNA accumulation and lower DSB recovery from HR (Xu et al. 2012; Jiang et al. 2015). Failure to remove H2A.Z at DSBs in human cells leads to higher RPA binding and higher recovery from HR (Gursoy-Yuzugullu et al. 2015). In fission yeast, H2A.Z is a known substrate of Mst1, and a mutant pht1-4KR that disrupts the Mst1 acetylation sites causes genome instability and anaphase defects (Kim et al. 2009). To investigate the role of H2A.Z acetylation in repair, we compared the phenotype of pht1-4KR and pht1s to mst $1-L 344 S$. We observed significant reduction in RPA and $\operatorname{Rad} 52$ foci in $p h t 1-4 K R$ at $25^{\circ} \mathrm{C}$ similar to that observed with $m s t 1-L 344 S$ cells (Figure 2A, supplementary figure 2B, supplementary table 1). However, in contrast to mst1-L344S, the sensitivity to bleomycin we observe in $p h t 1-4 K R$ is not rescued by $p k u 70 \Delta$ (Figure $3 \mathrm{~B}$ ). 
261 We also compared the phenotypes of pht $1 \Delta$ and pht1-4KR cells. pht1 $\Delta$ showed fewer cells with RPA

262 foci compared to wild type under phleomycin treatment (Figure 2A, supplementary figure 2B, supplementary

263 table 1). Rad52 foci were also reduced in pht1 $\Delta$ compared to wild type under phleomycin treatment (Figure

$2642 \mathrm{~A})$. However, the effect of $p h t 1-4 K R$ cells was more dramatic than $p h t 1 \Delta$, and much closer to the observations

265 in mst1-L344S (Figure 2A, supplementary table 1). Finally, we used the mCherry-DSB reporter system to

266 examine resection in vivo. As with $m s t 1-L 344 S$ and exol 1 , pht 1-4KR cells showed a persistent mCherry-DSB

267 signal, consistent with a failure to resect (Figure 2D).

\section{The damage checkpoint is normal in mst1-L344S}

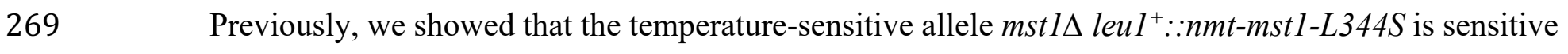
270 to S-phase specific genotoxins including methyl methanesulfonate (MMS), which causes alkylation damage 271 that inhibits replication, and camptothecin (CPT), a topoisomerase-I inhibitor that causes lesions during S272 phase (Wan et al. 1999; Fung et al. 2002; Morishita et al. 2003; Frampton et al. 2006). In contrast to our 273 observations with phleomycin, which induces general DSBs, we observed that the percentage of cells with 274 RPA and Rad52 foci was higher in $m s t 1-L 344 S$ cells treated with these S-phase specific genotoxins than that 275 in wild-type (Figure 4A). This is consistent with these S-phase specific lesions inducing different repair 276 pathways, including post-replication repair via translesion synthesis and template switching to repair MMS277 induced damage, as well as nucleolytic cleavage of protein -DNA adducts to repair CPT-induced damages (rev. 278 in (Alagoz et al. 2012; Arbel, Liefshitz, and Kupiec 2020)).

279 We examined genetic interactions between mst1-L344S and mutants that affect checkpoint under 280 treatment with a variety of S-phase specific genome stressors (Supplementary figure 4). A modest growth 281 defect in untreated cells was observed for the double mutant mst1-L344S rad3 $\Delta$ but not for others. In cells 282 treated with UV or MMS at $25^{\circ} \mathrm{C}$, we observed a striking negative interaction between $m s t 1-L 344 S$ and damage 283 checkpoint mutants $\operatorname{chk} 1 \Delta$ or $\operatorname{crb} 2 \Delta$ at $25^{\circ} \mathrm{C}$, suggesting a requirement for an active damage checkpoint 284 response under these treatments. This data is consistent with previous findings in S. cerevisiae that the cell 285 cycle delay in NuA4 mutant depends on Rad9 (SpCrb2 ortholog) after DSB induction (Javaheri et al. 2006). 286 We treated cells with MMS, CPT or hydroxyurea (HU) and performed western blots against HA tagged Chk1. 287 In wild-type, Chk1 is phosphorylated in cells treated with four-hour CPT or MMS, but not in untreated cells 288 or cells treated with HU (Figure 4B; Walworth and Bernards 1996). We observed a largely similar 289 phosphorylation pattern in $m s t 1-L 344 S$ mutant (Figure 4B), although there may be a modest reduction in the 290 amount of pChk1. H2A phosphorylation, one of the first sensors of DNA damage and double strand breaks, 291 was also present in mst1-L344S cells after 4-hour CPT treatment as in wild-type cells and diminished after 292 removing drugs from cell culture (Figure 4C). Mst1 is not required for checkpoint activation in response to S293 phase specific lesions but depends on that response for viability. 


\section{Discussion}

296

297

298

299

300

301

302

303

304

305

306

307

308

309

310

311

312

313

314

315

316

317

318

319

320

321

322

323

324

The MYST protein Mst1 (hTIP60; ScEsa1; KAT5) is the catalytic subunit of the NuA4 histone acetyltransferase complex, and makes pleiotropic contributions to genome stability (rev. in (Lafon et al. 2007; Pillus 2008)). Multiple studies indicate that hTIP60 and ScEsal contribute to DSB repair through acetylation (rev. in (Ghobashi and Kamel 2018)), and show that the acetyltransferase binds near DSB regions (Downs et al. 2004; Sun et al. 2009; Xu et al. 2010; Li and Wang 2017; Cheng et al. 2018). The budding yeast ScEsa1 acetylates ssDNA binding protein RPA at DSBs (Cheng et al. 2018) and in mammalian cells, TIP60 promotes HR localization of recombination protein Rad51 (Murr et al. 2005).

Previously we showed that Mst1 is $S$. pombe is essential for viability and we demonstrated the temperature sensitive allele mst1-L344S is sensitive to a number of genotoxins (Gómez et al. 2008; Gómez, Espinosa, and Forsburg 2005). Here, we confirmed that Mst1 in S. pombe is important for DSB repair because both temperature sensitive alleles are sensitive to a DSB-inducing environment including treatment with phleomycin or bleomycin, or constitutive HO-nuclease expression (Figure 1A, 1C, 3 and supplementary figure 1). We find that Mst1 directly localizes to DSBs, and this localization depends on H3K9 ${ }^{\text {me }}$ (Figure 1E and Figure 5). We observe that even under permissive growth conditions, mst1-L344S shifts the balance of repair away from HR towards SSA or NHEJ (Figure 1D). We also observed that a lower percentage of $m s t 1-L 344 S$ cells compared to wild type show visible foci of HR associated proteins RPA, Rad52 or Rad54, following treatment with DSB inducing agents (Figure 2A, B). Together, these observations suggest that Mst1 facilitates homologous recombination to repair DSBs, and in its absence, HR is impaired (Figure 5).

There are conflicting data as to whether KAT5/NuA4 influences non-homologous end joining (NHEJ), which is typically the alternative pathway for repair if HR is inhibited (Chang et al. 2017). In budding yeast, ScEsa1 has been reported to be essential for NHEJ at DSBs (Bird et al. 2002). However, studies in mammalian cells suggest TIP60 instead inhibits NHEJ by acetylating H2A and H4; this reduces loading of 53BP1 protein that promotes NHEJ (Tang et al. 2013; Renaud et al. 2015; Jacquet et al. 2016). Consistent with this, in budding yeast deletion of the 53BP1 orthologue Scrad9 increases resection efficiency (Bonetti et al. 2015) and similarly, fission yeast $c r b 2 \Delta$ mutants have increased resection (Leland et al. 2018). However, in fission yeast, the G2-dominant cell cycle means that NHEJ is generally not the preferred pathway for DSB repair in growing cells (rev. in (Langerak and Russell 2011)). Because of this, we did not specifically examine efficiency of NHEJ. Our data suggest that Mst1 affects homologous recombination, specifically by reducing long-range resection (Figure 2 and Figure 5). 
To monitor resection, we used a visual assay in which a lacO array marked by lacI-mCherry is adjacent

to an induced double strand break. Previous studies have shown that loss of the lacO array adjacent to a break correlates with resection ( $\mathrm{Yu}$ et al. 2013; Leland et al. 2018). Consistent with this, we find that the mCherry signal declines over time in a wild type in the presence of the induced break, but not in an exol $\Delta$ mutant that lacks the long-range exonuclease. We also observe that mst1-L344S resembles exo1 $\Delta$ in this assay. The data from this, as well as the mutant sensitivity to DSB-inducing drugs, suggest that mst 1 and exol are in a common epistasis group (Figure 5).

The end-binding protein complex $\mathrm{Ku}$ inhibits resection and thus, homologous recombination (rev. in 333 (Shibata, Jeggo, and Löbrich 2018)). Its activity is coordinated with the Mre11-Rad50-Nbs1 (MRN) complex 334 associated with early steps in resection (rev. in (Shibata, Jeggo, and Löbrich 2018; Syed and Tainer 2018)). 335 While $\mathrm{Ku}$ inhibits resection driven by $\mathrm{MRN}, \mathrm{MRN}$ removes $\mathrm{Ku}$ to facilitate homologous recombination (HR) 336 over NHEJ (Langerak and Russell 2011; Shao et al. 2012; Myler et al. 2017; Shibata et al. 2018). Previous work has shown that $p k u 70 \Delta$ rescues some resection in the absence of the MRN complex (Tomita et al. 2003; Langerak et al. 2011; Teixeira-Silva et al. 2017). Consistent with these observations, we found pku70د also partially rescues mstl and mstl exols sensitivity to DSB-inducing agents, and partly restores recruitment of HR proteins and resection. This agrees with a model that Pku70 inhibits an alternative resection pathway that is independent of MRN, Mst1, or Exo1.

However, we observe an intermediate effect of $\mathrm{Pku} 70$ on resection in our visual assay: unexpectedly pku70s showed stabilization of the mCherry-LacI signal in both wild type and mst1-L344S backgrounds, whereas we expected at least the single mutant to show wild type levels of resection. Since Pku70 represses microhomology-mediated end joining (MMEJ), one possibility is that an increase of MMEJ antagonizes resection directly (Decottignies 2007; Wang and $\mathrm{Xu}$ 2017). This may also distinguish a role for $\mathrm{Ku}$ in the initiation of resection (which is Exo1-independent) from long range resection, which is likely required to see loss of the mCherry-LacI signal and could be antagonized by MMEJ in our assay. Ku also plays a role in telomere maintenance (Baumann and Cech 2000; Manolis et al. 2001), in replication fork restart (TeixeiraSilva et al. 2017), and in rDNA stability (Miyoshi et al. 2009; Sánchez and Russell 2015). It represses chromosome rearrangements (Prudden et al. 2003). We observed increased RPA signal in the pku70 mutant without any treatment, suggesting the loss of Pku70 causes an increased burden of ssDNA. It is possible that efficiency of resection at a single engineered break is reduced due to recruitment of resection activities to numerous other sites of genotoxic stress that are the result of $\mathrm{Ku}$ depletion, but this observation will require further analysis.

Multiple studies show the presence and the turnover of the histone variant H2A.Z (SpPht1) is required 
358 mammalian cells, the absence of H2A.Z leads to more ssDNA accumulation and reduced Pku70 localization

359 (Xu et al. 2012; Gursoy-Yuzugullu et al. 2015). Exchange of H2A.Z is required for H4 acetylation by TIP60, 360 which creates open chromatin (Gursoy-Yuzugullu, Ayrapetov, and Price 2015; Xu et al. 2010, 2012). Several 361 acetyltransferases have been implicated in H2A.Z acetylation including KAT5 (Mst1) and KAT2A (Gcn5) 362 (Kusch et al. 2004; Babiarz et al. 2006; Keogh et al. 2006; Millar et al. 2006; Zlatanova and Thakar 2008; 363 Kim et al. 2009; Semer et al. 2019). In mammalian cells, the deposition of H2A.Z precedes its acetylation (Xu 364 et al. 2012), while in Drosophila, the acetylation of H2A.Z homolog H2Av stimulates its removal after DNA 365 damage (Kusch et al. 2004). Blocking TIP60 prevents both H2A.Z exchange and H4 acetylation (Morillo366 huesca et al. 2010; Papamichos-Chronakis et al. 2011; Xu et al. 2012; Shastri et al. 2018).

To investigate whether H2A.Z acetylation by Mst1 influences repair, we used a non-acetylable mutant of H2A.Z, pht1-4KR. This mutation has previously been shown to disrupt Mst1 acetylation sites and leads to chromosome segregation errors (Kim et al. 2009). We saw a similar percentage of pht1-4KR cells with RPA and Rad52 foci as seen in mst1-L344S cells in treated cells, both significantly lower than that in wild type. Additionally, mCherry-DSB foci in pht1-4KR did not disappear across the time-course, and the percentage of mCherry-DSB persistence was similar to that in mst1-L344S (Figure 2D). This suggests that pht1-4KR and $m s t 1-344 S$ affect in a common pathway required for resection. We speculate that pht1-4KR once inserted cannot be efficiently removed, and interferes with $\mathrm{H} 4$ acetylation and chromatin decompaction. This would essentially lock the chromatin in a form refractory to long range resection. This could explain why sensitivity of pht $1-4 K R$ to DSBs is more severe than that of pht $1 \Delta$, suggesting that an immobile H2A.Z is more damaging than no $\mathrm{H} 2 \mathrm{~A} . \mathrm{Z}$ at all. However, in contrast to $m s t 1$, pht $1-4 K R$ sensitivity to bleomycin is not rescued by $p k u 70 \Delta$ (Figure 3B). This might suggest that H2A.Z binds to DSBs after Pku70 is removed, but that would be inconsistent with work in mammalian cells suggesting that Ku-recruitment is H2A.Z dependent (Xu et al. 2012). Further work will be required to resolve these observations.

Finally, we show that the temperature sensitive allele $m s t 1 \Delta$ leu1 $1^{+}: n m t: m s t 1-L 344 S$ is sensitive to $\mathrm{S}$ phase specific genotoxins including methyl methanesulfonate (MMS) and camptothecin (CPT) even at permissive temperature (Gómez et al. 2008). This is consistent with a recent study showing that Mst1 in $S$. pombe is important for CPT-induced damge repair (Noguchi et al. 2019). Studies in S. cerevisiae showed Esal's importance to MMS-induced damage repair through translesion synthesis and sister chromatid recombination (Bird et al. 2002; House et al. 2014; Renaud-Young et al. 2015). Compromised DNA damage repair could be the result of defective damage checkpoint activation. In mammalian cells, TIP60 is known to acetylate ATM and p53 (Sun et al. 2005; Sykes et al. 2006; Tang et al. 2006). However, we find that the temperature sensitive allele does not affect activation of DNA damage checkpoint Chk1 or phosphorylation of $\mathrm{H} 2 \mathrm{~A}(\mathrm{X})$ (Figure 4B and C). 
391 Taken together, our data suggest that SpMst1contributes to repair of a variety of DNA lesions. As in 392 other organisms, our data show that Mst1 acetyltransferase has a particular role in double strand break repair, 393 where it facilitates homologous recombination by promoting long range resection and antagonizing NHEJ394 promoting factors such as $\mathrm{Ku}$ (Figure 5). Our data suggest that this depends on acetylation of H2A.Z. The 395 conservation of function of this acetyltransferase across eukaryotes indicates the fundamental nature of 396 chromatin modification in DNA repair transactions.

398 Acknowledgement

399 We would like to thank Li-Lin Du, Michael Keogh, Takuro Nakagawa, Eishi Noguchi, Mathew 400 O'Connell, and Simon Whitehall for strains. We thank Ji-Ping Yuan and Amanda Jensen for assistance and 401 technical support. We are grateful to current members of the Forsburg lab for many helpful comments and 402 discussions throughout the course of the study, and an anonymous reviewer for helpful suggestion. This work 403 was supported by NIH R35 GM118109 (SLF). 


\section{References}

406 Ahn J. S., F. Osman, and M. C. Whitby, 2005 Replication fork blockage by RTS1 at an ectopic site promotes recombination in fission yeast. EMBO J. 24: 2011-2023. https://doi.org/10.1038/sj.emboj.7600670

Alagoz M., D. C. Gilbert, S. El-Khamisy, and A. J. Chalmers, 2012 DNA Repair and Resistance to Topoisomerase I Inhibitors: Mechanisms, Biomarkers and Therapeutic Targets. Curr. Med. Chem. 19: 3874-3885. https://doi.org/10.2174/092986712802002590

Aleksandrov R., R. Hristova, S. Stoynov, and A. Gospodinov, 2020 The Chromatin Response to DoubleStrand DNA Breaks and Their Repair. Cells 9. https://doi.org/10.3390/cells9081853

Allard S., R. T. Utley, J. Savard, A. Clarke, P. Grant, et al., 1999 The NuA4 transcription activation/histone H4 acetyltransferase complex contains the essential Esa1 protein as the catalytic subunit and the essential ATM-related cofactor Tra1p. Biochem. Cell Biol. 77: 5108-5119. https://doi.org/10.1139/o99903

Arbel M., B. Liefshitz, and M. Kupiec, 2020 How yeast cells deal with stalled replication forks. Curr. Genet. 66: 911-915. https://doi.org/10.1007/s00294-020-01082-y

Avvakumov N. ., and J. Côté, 2007 The MYST family of histone acetyltransferases and their intimate links to cancer. Oncogene 26: 5395-5407. https://doi.org/10.1038/sj.onc.1210608

Ayrapetov M. K., O. Gursoy-Yuzugullu, C. Xu, Y. Xu, and B. D. Price, 2014 DNA double-strand breaks promote methylation of histone H3 on lysine 9 and transient formation of repressive chromatin. Proc. Natl. Acad. Sci. 111: 9169-9174. https://doi.org/10.1073/pnas.1403565111

Babiarz J. E., J. E. Halley, and J. Rine, 2006 Telomeric heterochromatin boundaries require NuA4-dependent acetylation of histone variant H2A.Z in Saccharomyces cerevisiae. Genes Dev. https://doi.org/10.1101/gad.1386306

Bakkenist C. J., and M. B. Kastan, 2015 Chromatin perturbations during the DNA damage response in higher eukaryotes. DNA Repair (Amst). 36: 8-12. https://doi.org/10.1016/j.dnarep.2015.09.002

Baumann P., and T. R. Cech, 2000 Protection of telomeres by the Ku protein in fission yeast. Mol. Biol. Cell. https://doi.org/10.1091/mbc.11.10.3265

Belenguer P., M.-L. Oustrin, G. Tiraby, and B. Ducommun, 1995 Effects of phleomycin-induced DNA damage on the fission yeast Schizosaccharomyces pombe cell cycle. Yeast 11:225-231. https://doi.org/10.1002/yea.320110305

Bird A. W., D. Y. Yu, M. G. Pray-Grant, Q. Qiu, and M. F. Christman, 2002 Acetylation of histone H4 by Esal is required for DNA double-strand break repair. Nature 419: 411-415. 
reduces the requirement for Sae2 and functional MRX in DNA end resection . EMBO Rep. 16: 351-

361. https://doi.org/10.15252/embr.201439764

Burger R. M., 1998 Cleavage of Nucleic Acids by Bleomycin. 2665: 16-19.

https://doi.org/10.1021/cr960438a

Chang H. H. Y., N. R. Pannunzio, N. Adachi, and M. R. Lieber, 2017 Non-homologous DNA end joining and alternative pathways to double-strand break repair. Nat. Rev. Mol. Cell Biol. 18: 495-506. https://doi.org/10.1038/nrm.2017.48

Cheng X., O. Jobin-robitaille, P. Billon, R. Buisson, V. Côté, et al., 2018 Phospho-dependent recruitment of 446 NuA4 by MRX at DNA breaks regulates RPA dynamics during resection. Proc. Natl. Acad. Sci. U. S. A. 6: P93. https://doi.org/10.1186/1756-8935-6-S1-P93

Clarke T. L. ., M. P. Sanchez-Bailon, K. Chiang, J. J. . Reynolds, J. Herrero-Ruiz, et al., 2017 PRMT5-

Recombination. Mol. Cell 65: 900-916. https://doi.org/10.1016/j.molcel.2017.01.019

Clouaire T., and G. Legube, 2019 A Snapshot on the Cis Chromatin Response to DNA Double-Strand

Breaks. Trends Genet. 35: 330-345. https://doi.org/10.1016/j.tig.2019.02.003

Decottignies A., 2007 Microhomology-mediated end joining in fission yeast is repressed by Pku70 and relies on genes involved in homologous recombination. Genetics 176: 1403-1415. https://doi.org/10.1534/genetics.107.071621

457

458

459

460

461

462

463

464

465

466

467

468

469

470

Dhar S., O. Gursoy-Yuzugullu, R. Parasuram, and B. D. Price, 2017 The tale of a tail: Histone H4 acetylation and the repair of DNA breaks. Philos. Trans. R. Soc. B Biol. Sci. 372. https://doi.org/10.1098/rstb.2016.0284

Downs J. A., S. Allard, O. Jobin-Robitaille, A. Javaheri, A. Auger, et al., 2004 Binding of chromatinmodifying activities to phosphorylated histone H2A at DNA damage sites. Mol. Cell 16: 979-990. https://doi.org/10.1016/j.molcel.2004.12.003

Downs J. A., and S. P. Jackson, 2004 A means to a DNA end: The many roles of Ku. Nat. Rev. Mol. Cell Biol. 5: 367-378. https://doi.org/10.1038/nrm1367

Doyon Y., and J. Côté, 2004 The highly conserved and multifunctional NuA4 HAT complex. 2 14: 147-154. https://doi.org/10.1016/j.gde.2004.02.009

Doyon Y., W. Selleck, W. S. Lane, S. Tan, and J. Côté, 2004 Structural and functional conservation of the $\mathrm{NuA} 4$ histone acetyltransferase complex from yeast to humans. Mol. Cell. Biol. 24: 1884-96. https://doi.org/10.1128/MCB.24.5.1884

Du L. L., T. M. Nakamura, and P. Russell, 2006 Histone modification-dependent and -independent pathways for recruitment of checkpoint protein Crb2 to double-strand breaks. Genes Dev. 20: 1583-1596. 
Fell V. L., and C. Schild-Poulter, 2015 The Ku heterodimer: Function in DNA repair and beyond. Mutat.

Res. - Rev. Mutat. Res. 763: 15-29. https://doi.org/10.1016/j.mrrev.2014.06.002

Fortunato E. A., F. Osman, and S. Subramani, 1996 Analysis of spontaneous and double-strand breakinduced recombination in rad mutants of S. pombe. Mutat. Res. - DNA Repair 364: 147-160. https://doi.org/10.1016/S0921-8777(96)00022-5

Frampton J., A. Irmisch, C. M. Green, A. Neiss, M. Trickey, et al., 2006 Postreplication Repair and PCNA Modification in Schizosaccharomyces pombe. Mol. Biol. Cell 17: 2976-2985. https://doi.org/10.1091/mbc.E05

Fung A. D., J. Ou, S. Bueler, and G. W. Brown, 2002 A Conserved Domain of Schizosaccharomyces pombe 481 dfp1+ Is Uniquely Required for Chromosome Stability following Alkylation Damage during S Phase.

482 Mol. Cell. Biol. 22: 4477-4490. https://doi.org/10.1128/mcb.22.13.4477-4490.2002

Galarneau L., A. Nourani, A. A. Boudreault, Y. Zhang, L. Héliot, et al., 2000 Multiple links between the 484 NuA4 histone acetyltransferase complex and epigenetic control of transcription. Mol. Cell. https://doi.org/10.1016/S1097-2765(00)80258-0

Garabedian M. V., C. Noguchi, M. A. Ziegler, M. M. Das, T. Singh, et al., 2012 The double-bromodomain proteins Bdf1 and Bdf2 modulate chromatin structure to regulate S-phase stress response in schizosaccharomyces pombe. Genetics 190: 487-500. https://doi.org/10.1534/genetics.111.135459

Ghobashi A. H., and M. A. Kamel, 2018 Tip60 : updates. Hum. Genet. 59: 161-168.

Gómez E. B., J. M. Espinosa, and S. L. Forsburg, 2005 Schizosaccharomyces pombe mst2+ encodes a

Gómez E. B., R. L. Nugent, S. Laria, and S. L. Forsburg, 2008 Schizosaccharomyces pombe histone acetyltransferase Mst1 (KAT5) is an essential protein required for damage response and chromosome segregation. Genetics 179: 757-771. https://doi.org/10.1534/genetics.107.085779

Green M. D. ., S. A. . Sabatinos, and S. L. . Forsburg, 2015 Microscopy Techniques to Examine DNA Replication in Fission Yeast. Methods Mol Biol 1300: 13-41. https://doi.org/10.1016/B978-0-12374984-0.00431-9

Gursoy-Yuzugullu O., M. K. . Ayrapetov, and B. D. . Price, 2015 Histone chaperone Anp32e removes 501 H2A.Z from DNA double-strand breaks and promotes nucleosome reorganization and DNA repair. Proc. Natl. Acad. Sci. 112: 7507-7512. https://doi.org/10.1073/pnas.1504868112

House N. C. M., J. H. Yang, S. C. Walsh, J. M. Moy, and C. H. Freudenreich, 2014 NuA4 Initiates Dynamic Histone H4 Acetylation to Promote High-Fidelity Sister Chromatid Recombination at Postreplication 
Gaps. Mol. Cell 55: 818-828. https://doi.org/10.1016/j.molcel.2014.07.007

505

506

507

508

509

510

511

512

513

514

515

516

517

518

519

520

521

522

523

524

525

526

527

528

529

530

531

532

533

534

535

536

Ikura T., S. Tashiro, A. Kakino, H. Shima, N. Jacob, et al., 2007 DNA Damage-Dependent Acetylation and Ubiquitination of H2AX Enhances Chromatin Dynamics. Mol. Cell. Biol. 27: 7028-7040.

https://doi.org/10.1128/MCB.00579-07

Jacquet K., A. Fradet-Turcotte, N. Avvakumov, J. P. Lambert, C. Roques, et al., 2016 The TIP60 Complex Regulates Bivalent Chromatin Recognition by 53BP1 through Direct H4K20me Binding and H2AK15 Acetylation. Mol. Cell 62: 409-421. https://doi.org/10.1016/j.molcel.2016.03.031

Javaheri A., R. Wysocki, O. Jobin-Robitaille, M. Altaf, J. Cote, et al., 2006 Yeast G1 DNA damage checkpoint regulation by H2A phosphorylation is independent of chromatin remodeling. Proc. Natl.

Acad. Sci. 103: 13771-13776. https://doi.org/10.1073/pnas.0511192103

Jha S., E. Shibata, and A. Dutta, 2008 Human Rvb1/Tip49 Is Required for the Histone Acetyltransferase Activity of Tip60/NuA4 and for the Downregulation of Phosphorylation on H2AX after DNA Damage. Mol. Cell. Biol. 28: 2690-2700. https://doi.org/10.1128/MCB.01983-07

Jiang X., Y. Sun, S. Chen, K. Roy, and B. D. Price, 2006 The FATC domains of PIKK proteins are functionally equivalent and participate in the Tip60-dependent activation of DNA-PKcs and ATM. J. Biol. Chem. 281: 15741-15746. https://doi.org/10.1074/jbc.M513172200

Jiang Y., X. Qian, J. Shen, Y. Wang, X. Li, et al., 2015 Local generation of fumarate promotes DNA repair through inhibition of histone H3 demethylation. Nat. Cell Biol. 17: 1158-1168.

https://doi.org/10.1038/ncb3209

Judes G., K. Rifaï, M. Ngollo, M. Daures, Y. J. Bignon, et al., 2015 A bivalent role of TIP60 histone acetyl transferase in human cancer. Epigenomics.

Kalocsay M., N. J. Hiller, and S. Jentsch, 2009 Chromosome-wide Rad51 Spreading and SUMO-H2A.ZDependent Chromosome Fixation in Response to a Persistent DNA Double-Strand Break. Mol. Cell 33: 335-343. https://doi.org/10.1016/j.molcel.2009.01.016

Keogh M., T. A. Mennella, C. Sawa, S. Berthelet, N. J. Krogan, et al., 2006 The Saccharomyces cerevisiae histone H2A variant Htz1 is acetylated by NuA4. Genes Dev. 20: 660-665. https://doi.org/10.1101/gad.1388106

Kim M.-Y., E.-J. Ann, J.-Y. Kim, J.-S. Mo, J.-H. Park, et al., 2007 Tip60 Histone Acetyltransferase Acts as a Negative Regulator of Notch1 Signaling by Means of Acetylation. Mol. Cell. Biol. https://doi.org/10.1128/mcb.01515-06

Kim H. S., V. Vanoosthuyse, J. Fillingham, A. Roguev, S. Watt, et al., 2009 An acetylated form of histone H2A.Z regulates chromosome architecture in Schizosaccharomyces pombe. Nat. Struct. Mol. Biol. 16: 1286-1293. https://doi.org/10.1038/nsmb.1688 
537 Kimura A., and M. Horikoshi, 1998 Tip60 acetylates six lysines of a specific class in core histones in vitro.

Genes to Cells 3: 789-800. https://doi.org/10.1046/j.1365-2443.1998.00229.x

Kobayashi J., A. Kato, Y. Ota, R. Ohba, and K. Komatsu, 2010 Bisbenzamidine derivative, pentamidine represses DNA damage response through inhibition of histone H2A acetylation. Mol. Cancer 9: 1-11. https://doi.org/10.1186/1476-4598-9-34

Kobor M. S., S. Venkatasubrahmanyam, M. D. Meneghini, J. W. Gin, J. L. Jennings, et al., 2004 A Protein Complex Containing the Conserved Swi2/Snf2-Related ATPase Swr1p Deposits Histone Variant H2A.Z into Euchromatin. PLoS Biol. 2: 4. https://doi.org/10.1097/GME.0000000000000420

Krogan N. J. ., K. Baetz, M. Keogh, N. Datta, C. Sawa, et al., 2004 Regulation of chromosome stability by the histone H2A variant Htz1, the Swrl chromatin remodeling complex, and the histone acetyltransferase NuA4. Proc. Natl. Acad. Sci. 101: 13513-13518.

Kusch T., L. Florens, W. H. MacDonald, S. K. Swanson, R. L. Glaser, et al., 2004 Acetylation by Tip60 is required for selective histone variant exchange at DNA lesions. Science (80-. ). 306: 2084-2087. https://doi.org/10.1126/science.1103455

La Cruz X. De, S. Lois, S. Sánchez-Molina, and M. A. Martínez-Balbás, 2005 Do protein motifs read the histone code? BioEssays.

Lafon A., C. S. Chang, E. M. Scott, S. J. Jacobson, and L. Pillus, 2007 MYST opportunities for growth control: Yeast genes illuminate human cancer gene functions. Oncogene 26: 5373-5384. https://doi.org/10.1038/sj.onc.1210606

Langerak P., E. Mejia-Ramirez, O. Limbo, and P. Russell, 2011 Release of Ku and MRN from DNA ends by

Langerak P., and P. Russell, 2011 Regulatory networks integrating cell cycle control with DNA damage checkpoints and double-strand break repair. Philos. Trans. R. Soc. B Biol. Sci. 366: 3562-3571. https://doi.org/10.1098/rstb.2011.0070

Leduc C., P. Claverie, B. Eymin, E. Col, S. Khochbin, et al., 2006 p14ARF promotes RB accumulation through inhibition of its Tip60-dependent acetylation. Oncogene. https://doi.org/10.1038/sj.onc.1209446 prevent RecQ helicase-dependent hyper-resection of DNA double-strand breaks. Elife 7: 1-14. https://doi.org/10.7554/eLife.33402 DNA double-strand break repair. J. Biol. Chem. 292: 11951-11959. 
Manolis K. G., E. R. Nimmo, E. Hartsuiker, A. M. Carr, P. A. Jeggo, et al., 2001 Novel functional requirements for non-homologous DNA end joining in Schizosaccharomyces pombe. EMBO J. 20: 210-221. https://doi.org/10.1093/emboj/20.1.210

Millar C. B. ., F. Xu, K. Zhang, and M. Grunstein, 2006 Acetylation of H2AZ Lys 14 is associated with genome-wide gene activity in yeast. Genes Dev. 20: 711-722. https://doi.org/10.1101/gad.1395506

Minoda A., S. Saitoh, K. Takahashi, and T. Toda, 2005 BAF53/Arp4 Homolog Alp5 in Fission Yeast Is Required for Histone H4 Acetylation, Kinetochore-Spindle Attachment, and Gene Silencing at Centromere. Mol. Biol. Cell 16: 316-327. https://doi.org/10.1091/mbc.E04

579

580

581

582

583

584

585

586

587

588

589

590

591

592

593

594

595

596

597

598

599

600

601

602

Miyoshi T., J. Kanoh, and F. Ishikawa, 2009 Fission yeast Ku protein is required for recovery from DNA replication stress. Genes to Cells. https://doi.org/10.1111/j.1365-2443.2009.01337.x

Morillo-huesca M., M. Clemente-ruiz, E. Andujar, and F. Prado, 2010 The SWR1 Histone Replacement Complex Causes Genetic Instability and Genome-Wide Transcription Misregulation in the Absence of H2A . Z. PLoS One 5. https://doi.org/10.1371/journal.pone.0012143

Morishita T., Y. Tsutsui, H. Iwasaki, and H. Shinagawa, 2003 The Schizosaccharomyces pombe rad60 Gene Is Essential for Repairing Double-Strand DNA Breaks Spontaneously Occurring during Replication and Induced by DNA-Damaging Agents. Mol. Cell. Biol. 23: 3373-3373. https://doi.org/10.1128/mcb.23.9.3373.2003

Murr R., J. I. Loizou, Y. G. Yang, C. Cuenin, H. Li, et al., 2005 Histone acetylation by Trrap-Tip60 modulates loading of repair proteins and repair of DNA double-strand breaks. Nat. Cell Biol. 8: 91-99. https://doi.org/10.1038/ncb1343

Myler L. R., I. F. Gallardo, M. M. Soniat, A. Rajashree, X. B. Gonzalez, et al., 2017 Single-molecule imaging reveals how Mre11-Rad50-Nbs1 initiates DNA break repair. Mol. Cell 67: 891-898. https://doi.org/10.1016/j.molcel.2017.08.002.Single-molecule

Naidu S. R., A. J. Lakhter, and E. J. Androphy, 2012 PIASy-mediated Tip60 sumoylation regulates p53induced autophagy. Cell Cycle 11: 2717-2728. https://doi.org/10.4161/cc.21091

Noguchi C., T. Singh, M. A. Ziegler, J. D. Peake, L. Khair, et al., 2019 The NuA4 acetyltransferase and histone $\mathrm{H} 4$ acetylation promote replication recovery after topoisomerase I-poisoning. Epigenetics and Chromatin 12: 1-17. https://doi.org/10.1186/s13072-019-0271-z

Nugent R. L., A. Johnsson, B. Fleharty, M. Gogol, Y. Xue-Franzén, et al., 2010 Expression profiling of S. pombe acetyltransferase mutants identifies redundant pathways of gene regulation. BMC Genomics 11. https://doi.org/10.1186/1471-2164-11-59

Onaka A. T., N. Toyofuku, T. Inoue, A. K. Okita, M. Sagawa, et al., 2016 Rad51 and Rad54 promote 
noncrossover recombination between centromere repeats on the same chromatid to prevent

isochromosome formation. Nucleic Acids Res. 44: 10744-10757. https://doi.org/10.1093/nar/gkw874

605

606

607

608

609

610

611

612

613

614

615

616

617

618

619

620

621

622

623

624

625

626

627

628

629

630

631

632

633

634

635

Ortega-Atienza S., V. C. Wong, Z. DeLoughery, M. W. Luczak, and A. Zhitkovich, 2016 ATM and KAT5 safeguard replicating chromatin against formaldehyde damage. Nucleic Acids Res. 44: 198-209. https://doi.org/10.1093/nar/gkv957

Osman F., E. A. Fortunato, and S. Subramani, 1996 Double-strand break-induced mitotic intrachromosomal recombination in the fission yeast Schizosaccharomyces pombe. Genetics 142: 341-357.

Osman F., M. Adriance, and S. McCready, 2000 The genetic control of spontaneous and UV-induced mitotic intrachromosomal recombination in the fission yeast Schizosaccharomyces pombe. Curr. Genet. 38: 113-125. https://doi.org/10.1007/s002940000145

Papamichos-Chronakis M., S. Watanabe, O. J. Rando, and C. L. Peterson, 2011 Global regulation of H2A.Z localization by the INO80 chromatin-remodeling enzyme is essential for genome integrity. Cell 144: 200-213. https://doi.org/10.1016/j.cell.2010.12.021

Pillus L., 2008 MYSTs mark chromatin for chromosomal functions. Curr. Opin. Cell Biol. 20: $326-333$. https://doi.org/10.1016/j.ceb.2008.04.009

Prudden J., J. S. Evans, S. P. Hussey, B. Deans, P. O’Neill, et al., 2003 Pathway utilization in response to a site-specific DNA double-strand break in fission yeast. EMBO J. https://doi.org/10.1093/emboj/cdg119

Renaud-Young M., D. C. Lloyd, K. Chatfield-Reed, I. George, G. Chua, et al., 2015 The NuA4 complex promotes translesion synthesis (TLS)-mediated DNA damage tolerance. Genetics 199: 1065-1076. https://doi.org/10.1534/genetics.115.174490

Renaud E., A. Barascu, and F. Rosselli, 2015 Impaired TIP60-mediated H4K16 acetylation accounts for the aberrant chromatin accumulation of 53BP1 and RAP80 in Fanconi anemia pathway-deficient cells. Nucleic Acids Res. 44: 648-656. https://doi.org/10.1093/nar/gkv1019

Sabatinos S. A., and S. L. Forsburg, 2010 Molecular genetics of schizosaccharomyces pombe. Methods Enzymol. 470: 759-795. https://doi.org/10.1016/S0076-6879(10)70032-X

Sánchez A., and P. Russell, $2015 \mathrm{Ku}$ Stabilizes replication forks in the absence of Brc1. PLoS One. https://doi.org/10.1371/journal.pone.0126598

Sapountzi V., I. R. Logan, and C. N. Robson, 2006 Cellular functions of TIP60. Int. J. Biochem. Cell Biol. 38: 1496-1509. https://doi.org/10.1016/j.biocel.2006.03.003

Scacchetti A., and P. B. Becker, 2021 Variation on a theme: Evolutionary strategies for H2A.Z exchange by SWR1-type remodelers. Curr. Opin. Cell Biol.

Schindelin J., I. Arganda-Carreras, E. Frise, V. Kaynig, M. Longair, et al., 2012 Fiji: An open-source platform for biological-image analysis. Nat. Methods. 
636 Schuchert P., and J. Kohli, 1988 The ade6-M26 Mutation of Schizosaccharomyces pombe Increases the Frequency of Crossing Over. Genetics 119: 507-515.

638 Semer M., B. Bidon, A. Larnicol, G. Caliskan, P. Catez, et al., 2019 DNA repair complex licenses acetylation of H2A.Z.1 by KAT2A during transcription. Nat. Chem. Biol. 15: 992-1000. https://doi.org/10.1038/s41589-019-0354-y

Shao Z., A. J. Davis, K. R. Fattah, S. So, J. Sun, et al., 2012 Persistently bound Ku at DNA ends attenuates DNA end resection and homologous recombination. DNA Repair (Amst). 11: 310-316.

644 https://doi.org/10.1016/j.dnarep.2011.12.007

Sharma G. G., S. So, A. Gupta, R. Kumar, C. Cayrou, et al., 2010 MOF and Histone H4 Acetylation at Lysine 16 Are Critical for DNA Damage Response and Double-Strand Break Repair. Mol. Cell. Biol. 30: 3582-3595. https://doi.org/10.1128/mcb.01476-09

Shastri N., Y. C. Tsai, S. Hile, D. Jordan, B. Powell, et al., 2018 Genome-wide Identification of StructureForming Repeats as Principal Sites of Fork Collapse upon ATR Inhibition. Mol. Cell 72: 222-238.e11. https://doi.org/10.1016/j.molcel.2018.08.047

Smith E. R., A. Eisen, W. Gu, M. Sattah, A. Pannuti, et al., 1998 ESA1 is a histone acetyltransferase that is 653 essential for growth in yeast. Proc Natl Acad Sci USA 95: 3561-3565. https://doi.org/10.1073/pnas.95.7.3561

655

Soria G., S. E. Polo, and G. Almouzni, 2012 Prime, Repair, Restore: The Active Role of Chromatin in the 656 DNA Damage Response. Mol. Cell 46: 722-734. https://doi.org/10.1016/j.molcel.2012.06.002

Stubbe J., and J. W. Kozarich, 1987 Mechanisms of Bleomycin-Induced DNA Degradation. Chem. Rev. 87: 1107-1136. https://doi.org/10.1021/cr00081a011

659

Sun Y., X. Jiang, S. Chen, N. Fernandes, and B. D. Price, 2005 A role for the Tip60 histone acetyltransferase 660 661 in the acetylation and activation of ATM. Proc. Natl. Acad. Sci. U. S. A. 102: 13182-13187. https://doi.org/10.1073/pnas.0504211102

663

Syed A., and J. A. Tainer, 2018 The MRE11-RAD50-NBS1 Complex Conducts the Orchestration of 263-294. https://doi.org/10.1146/annurev-biochem-062917-012415

Sykes S. M., H. S. Mellert, M. A. Holbert, K. Li, R. Marmorstein, et al., 2006 Acetylation of the p53 DNA- 
Binding Domain Regulates Apoptosis Induction. Mol. Cell 24: 841-851.

https://doi.org/10.1016/j.molcel.2006.11.026

671

672

673

674

675

676

677

678

679

680

681

682

683

684

685

686

687

688

689

690

691

692

693

694

695

696

697

698

699

700

701

Tang Y., J. Luo, W. Zhang, and W. Gu, 2006 Tip60-Dependent Acetylation of p53 Modulates the Decision between Cell-Cycle Arrest and Apoptosis. Mol. Cell 24: 827-839.

https://doi.org/10.1016/j.molcel.2006.11.021

Tang J., N. W. Cho, G. Cui, E. M. Manion, N. M. Shanbhag, et al., 2013 Acetylation limits 53BP1 association with damaged chromatin to promote homologous recombination. Nat. Struct. Mol. Biol. 20: 317-325. https://doi.org/10.1038/nsmb.2499

Teixeira-Silva A., A. Ait Saada, J. Hardy, I. Iraqui, M. C. Nocente, et al., 2017 The end-joining factor Ku acts in the end-resection of double strand break-free arrested replication forks. Nat. Commun. 8. https://doi.org/10.1038/s41467-017-02144-5

Thomas T., and A. K. Voss, 2007 The diverse biological roles of MYST histone acetyltransferase family proteins. Cell Cycle.

Tomita K., A. Matsuura, T. Caspari, A. M. Carr, Y. Akamatsu, et al., 2003 Competition between the Rad50 Complex and the Ku Heterodimer Reveals a Role for Exol in Processing Double-Strand Break. Mol. Cell. Biol. 23: 5186-5197. https://doi.org/10.1128/MCB.23.15.5186

Utley R. T., and J. Côté, 2003 The MYST family of histone acetyltransferases. Curr. Top. Microbiol. Immunol.

Van H. T., and M. A. Santos, 2018 Histone modifications and the DNA double-strand break response. Cell Cycle.

Voss A. K., and T. Thomas, 2009 MYST family histone acetyltransferases take center stage in stem cells and development. BioEssays.

Walworth N. C., and R. Bernards, 1996 rad-Dependent Response of the chk1-Encoded Protein Kinase at the DNA Damage Checkpoint. Science (80-. ). 271: 353-356.

Wan S., H. Capasso, and N. C. Walworth, 1999 The topoisomerase I poison camptothecin generates a Chk1dependent DNA damage checkpoint signal in fission yeast. Yeast 15: 821-828. https://doi.org/10.1002/(SICI)1097-0061(199907)15:10A<821::AID-YEA422>3.0.CO;2-\#

Wang H., and X. Xu, 2017 Microhomology-mediated end joining: New players join the team. Cell Biosci. 7: 4-9. https://doi.org/10.1186/s13578-017-0136-8

Xhemalce B., and T. Kouzarides, 2010 A chromodomain switch mediated by histone H3 Lys 4 acetylation regulates heterochromatin assembly. Genes Dev. 24: 647-652. https://doi.org/10.1101/gad.1881710

Xu Y., Y. Sun, X. Jiang, M. K. Ayrapetov, P. Moskwa, et al., 2010 The p400 ATPase regulates nucleosome stability and chromatin ubiquitination during DNA repair. J. Cell Biol. 191: 31-43. 
bioRxiv preprint doi: https://doi.org/10.1101/2020.06.03.132316; this version posted March 3, 2021. The copyright holder for this preprint

(which was not certified by peer review) is the author/funder, who has granted bioRxiv a license to display the preprint in perpetuity. It is made available under aCC-BY-NC-ND 4.0 International license.

https://doi.org/10.1083/jcb.201001160

703 Xu Y., M. K. Ayrapetov, C. Xu, O. Gursoy-Yuzugullu, Y. Hu, et al., 2012 Histone H2A.Z Controls a

704 Critical Chromatin Remodeling Step Required for DNA Double-Strand Break Repair. Mol. Cell 48:

705 723-733. https://doi.org/10.1016/j.molcel.2012.09.026

706 Yan Z., C. Xue, S. Kumar, J. B. Crickard, Y. Yu, et al., 2019 Rad52 Restrains Resection at DNA Double707 Strand Break Ends in Yeast. Mol. Cell 76: 699-711.e6. https://doi.org/10.1016/j.molcel.2019.08.017

708 Yu Y., J. Y. Ren, J. M. Zhang, F. Suo, X. F. Fang, et al., 2013 A proteome-wide visual screen identifies

709 fission yeast proteins localizing to DNA double-strand breaks. DNA Repair (Amst). 12: $433-443$.

710 https://doi.org/10.1016/j.dnarep.2013.04.001

711 Zhou B. O., S. S. Wang, L. X. Xu, F. L. Meng, Y. J. Xuan, et al., 2010 SWR1 Complex Poises

712 Heterochromatin Boundaries for Antisilencing Activity Propagation. Mol. Cell. Biol. 30: $2391-2400$.

713 https://doi.org/10.1128/MCB.01106-09

714 Zhu Z., W. H. Chung, E. Y. Shim, S. E. Lee, and G. Ira, 2008 Sgs1 Helicase and Two Nucleases Dna2 and 715 Exo1 Resect DNA Double-Strand Break Ends. Cell 134: 981-994.

716 https://doi.org/10.1016/j.cell.2008.08.037

717 Zlatanova J., and A. Thakar, 2008 H2A.Z: View from the Top. Structure 16: 166-179. https://doi.org/10.1016/j.str.2007.12.008 


\section{Figure Legends}

721 Figure 1. The mst1-L344S allele affects DSB repair. A. $m s t 1-L 344 S$ are sensitive to bleomycin. Cells were 722 grown in YES media overnight at $25^{\circ} \mathrm{C}$ then $5 \mathrm{X}$ serial dilutions were spotted onto YES plates or YES plates 723 containing bleomycin. Plates were incubated at $25^{\circ} \mathrm{C}$ and photographed after 4 days. 1 unit of bleomycin $=1$ $724 \mathrm{mg}$ (by potency). B. An assay to test chromosomal instability from (Osman et al. 1996). Two non-functional 725 ade6 alleles flank the functional $\mathrm{ura}^{+}$gene. the ade6-L469 has a mutation at the C terminus while the ade6726 M26 allele has a mutation at the N-terminus (indicated by the vertical lines). Several recombination outcomes 727 are possible and are described in results and methods. C. Cells were grown in YES media overnight at $25^{\circ} \mathrm{C}$ 728 then $5 \mathrm{X}$ serial dilutions were spotted onto YES (HO repressed) or PMG without thiamine (HO induced). Plates 729 were incubated at $25^{\circ} \mathrm{C}$ and photographed after 5 days. D. Percent of deletion, conversion and complex 730 rearrangements after double strand break induction in WT and mst1-L344S using the assay in B. The bold line 731 in each box represents median and the filled circles represent outliers. Asterisks indicate that recombination 732 percentage is significantly different than WT $(\mathrm{p}<0.05$, Mann-Whitney Test $)$. E. Chromatin 733 immunoprecipitation assay to test recruitment of Rad52-YFP and Mst1-V5 to a single DNA double strand 734 break in WT and clr4 $\Delta$. Using a construct from Du, Nakamura, and Russell 2006 with one single double strand 735 break can be made with the $H O$ endonuclease and protein interaction with chromatin can be monitored at 0.2 736 and $2 \mathrm{~KB}$ from the break. Following break induction, time points were taken at 0, 22, 24 and 26 hours. qPCR 737 was done with primers provided in Du, Nakamura, and Russell 2006. Asterisks represent fold enrichment is 738 significantly different than that in WT ( $<<0.1$, Student's t-test). F. clr $4 \Delta$ had lower percentage of cells with 739 Rad52 foci after single DSB induction. Top: Percentage of cells with Rad52 foci using a construct from Du, 740 Nakamura, and Russell 2006 with one single double strand break can be made with the $H O$ endonuclease. 741 Following break induction, cultures were taken at 0, 22, 24 and 26 hours as in Figure 1E and cells were imaged 742 under microscope. Asterisks represent fold enrichment is significantly different than that in WT ( $<<0.05$,

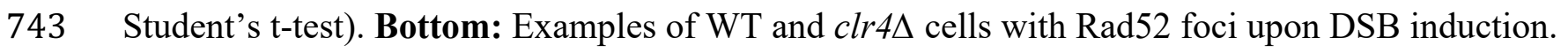

744 Figure 2. The mst1-L344S mutant affects recruitment of repair proteins at $\mathbf{2 5}^{\circ} \mathrm{C}$ A. Top: Percentage of

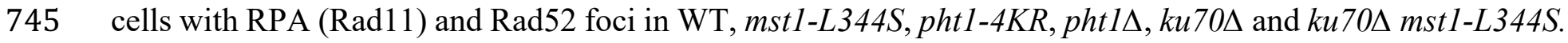

746 The bold line in each box represents median and the filled circles represent outliers. Asterisks represent 747 percentage of cells with foci is significantly different than that in WT $(*: \mathrm{p}<0.05, * *: \mathrm{p}<0.01$, Mann-Whitney 748 Test) Bottom: Examples of WT and mst1-L344S cells with Rad11 and Rad52 foci. Scale bar is 10 $\mu \mathrm{m}$. Rad11749 CFP is colored magenta for visibility. B. Top: Percentage of cells with Rad54 foci in WT and mst1-L344S,

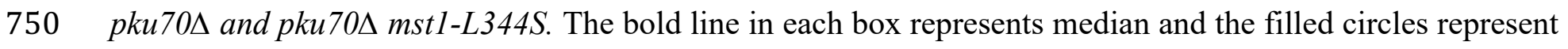
751 outliers. Bottom: Examples of WT and mst1-L344S cells with Rad54 foci under phleomycin treatment. Scale 752 bar is $10 \mu \mathrm{m}$. C. Top: Percentage of cells with colocalized Rad52-CFP and HO-induced mCherry foci over 
753240 minutes. Bottom: Representatives of WT and mst1-L344S cells with Rad52-CFP and HO-induced

754 mCherry foci over time. Rad52-CFP is colored green for visibility. D. Percentage of cells with mCherry-LacI

755 signal over 240 minutes. Image was taken every $8 \mathrm{~min}$ in wild-type and $m s t 1-L 344 S$, and every $48 \mathrm{~min}$ in other 756 mutants.

757 Figure 3. $m s t 1-L 344 S$ mutants are sensitive to the DSB-inducing agent bleomycin. $p k u 70 \Delta$, exo $1 \Delta \mathrm{A}$. and 758 pht1-4KR B. growth in bleomycin. Cells were grown in YES media overnight at $25^{\circ} \mathrm{C}$ then $5 \mathrm{X}$ serial dilutions 759 were spotted onto YES plates or YES plates containing bleomycin. Plates were incubated at $25^{\circ} \mathrm{C}$ and 760 photographed after 4 days. 1 unit of bleomycin $=1 \mathrm{mg}$ (by potency)

761 Figure 4. Mst1 affects DNA lesion repair but does not affect checkpoint activation. A. Left: Percentage 762 of cells with RPA (Rad11) and Rad52 foci in WT and mst1-L344S after CPT and MMS treatments. The bold 763 line in each box represents median and the filled circles represent outliers. Right: examples of WT and mst 1 $764 L 344 S$ cells with RPA and Rad52 foci after drug treatment. Scale bar is $10 \mu \mathrm{m}$. Rad11-CFP is colored magenta 765 for visibility. B. Phosphorylation of Chk1-HA is not affected in mstl-L344S after treatment of cells with three 766 types of DNA damaging agents at $32^{\circ} \mathrm{C}$. cells were treated for 4 hours with $0.01 \% \mathrm{MMS}, 15 \mathrm{mM} \mathrm{HU}$ or $40 \mu \mathrm{M}$ 767 CPT and the and the Chk1-HA phosphorylation shift band was detected by Western blotting with 12CA5 anti768 HA antibody. C. H2A phosphorylation dynamics are not affected in mst $1-L 344 S$ when cells are treated with $76940 \mu \mathrm{M} \mathrm{CPT}$. Western Blot with an anti-phosphorylated H2A antibody showing that phosphorylation of H2A 770 peaks 4 hours after treatment with drug then the signal is down regulated 4 hours post drug removal. htal771 S129A: control non-phosphorylatable form of H2A; $\alpha$-PCNA: control antibody.

772 Figure 5. Model for the function of Mst1 in DSB repair. Mst1 facilitates HR by promoting long-range 773 resection and inhibiting Ku70-associated mechanism that inhibits HR. Such function is accomplished by 774 acetylating H2A.Z and thus promoting the turnover of H2A.Z at the DSB. Therefore, the histone variant can 775 no longer block the break site. The removal of H2A.Z allows Exo1 to access the break and thus promotes 776 downstream recombination-mediated repair.

777 Supplementary Figure S1. mst1-L344S mutants are sensitive to Bleomycin analog Phleomycin. Cells 778 were grown in YES media overnight at $25^{\circ} \mathrm{C}$ then $5 \mathrm{X}$ serial dilutions were spotted onto YES plate or YES 779 plates containing Phleomycin. Plates were incubated at $25^{\circ} \mathrm{C}$ and photographed after 4 days.

780 Supplementary Figure S2. Examples of cells with RPA (Rad11), Rad52, and Rad54 foci after treatment 781 with phleomycin at $25^{\circ} \mathbf{C}$. A. Rad11-CFP and Rad52-YFP foci in pku704 and pku704 mst1-L344S. B. Rad11782 CFP and Rad52-YFP foci in pht1-4KR and pht14. C. Rad54-GFP foci in pku704 and pku704 mst1-L344S.

783 Supplementary Figure S3. pku $70 \Delta$ does not affect cell length at septation in mst1-L344S at $25^{\circ} \mathrm{C}$. Length

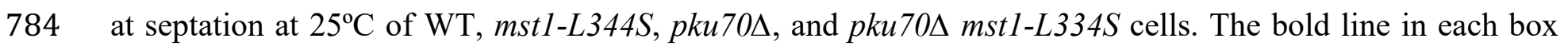
785 represents median and the filled circles represent outliers. 
bioRxiv preprint doi: https://doi.org/10.1101/2020.06.03132316; this version posted March 3, 2021. The copyright holder for this preprint (which was not certified by peer review) is the author/funder, who has granted bioRxiv a license to display the preprint in perpetuity. It is made available under aCC-BY-NC-ND 4.0 International license.

\section{Supplementary Figure S4. mst1-L344S interacts genetically with genes in the checkpoint pathways. Cells}

787 were grown in YES media overnight at $32^{\circ} \mathrm{C}$ then $5 \mathrm{X}$ serial dilutions were spotted onto YES plate or YES 788 plates containing the indicated drugs. Plates were incubated at $32^{\circ} \mathrm{C}$ and photographed after 4 days.

789 Supplementary Table S1. Median, first and third quantiles of cells with Rad11, Rad52 or Rad54 percentage 790 shown in Figure 2A and 2B.

791 Supplementary Table S2. Strains used in this study. 
bioRxiv preprint doi: https://doi.org/10.1101/2020.06.03.132316; this version posted March 3, 2021. The copyright holder for this preprint (which was not certified by peer review) is the author/funder, who has granted bioRxiv a license to display the preprint in perpetuity. It is made available under aCC-BY-NC-ND 4.0 International license.

Figure 1. The mst1-L344S allele affects DSB repair.

A

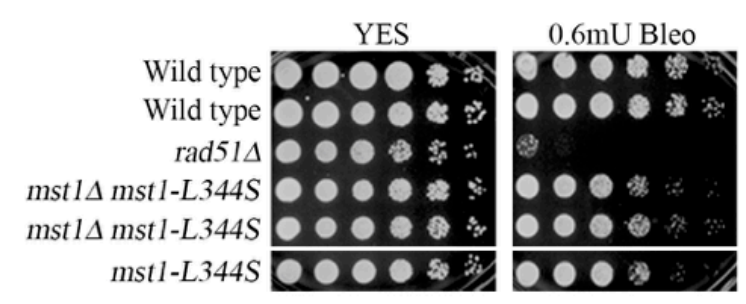

B

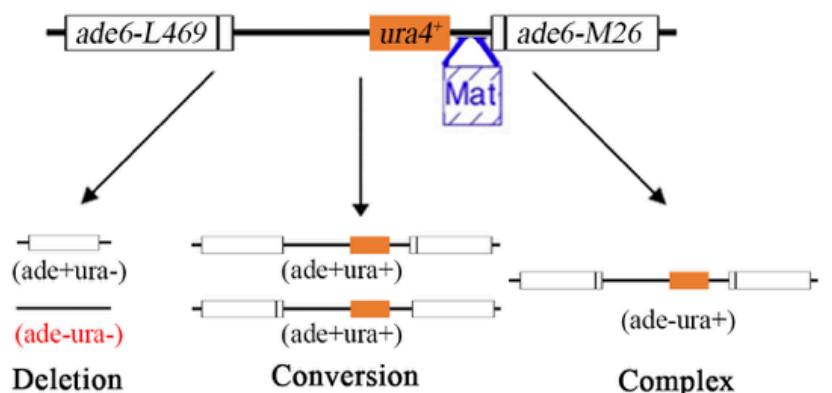

Unequal exchange Replication fork

Single Strand Annealing regression

Loop-out and mismatch repair

Gap repair and

crossing-over

E

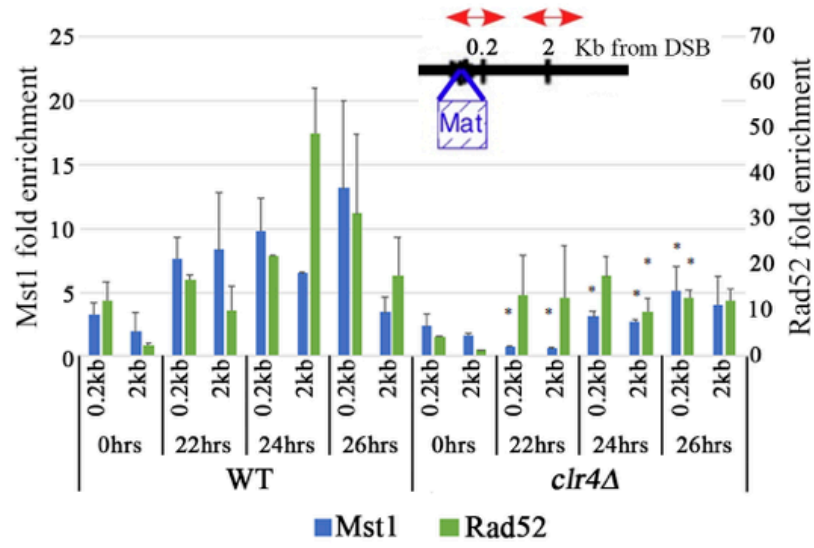

C

\begin{tabular}{|c|c|}
\hline $\mathrm{HO}$ repressed & $\mathrm{HO}$ induced \\
\hline 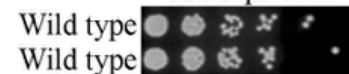 & $\begin{array}{l}0 \\
0\end{array}$ \\
\hline $\begin{array}{l}t 1-L 344 S \\
t l-L 344 S\end{array}$ & \\
\hline
\end{tabular}

D

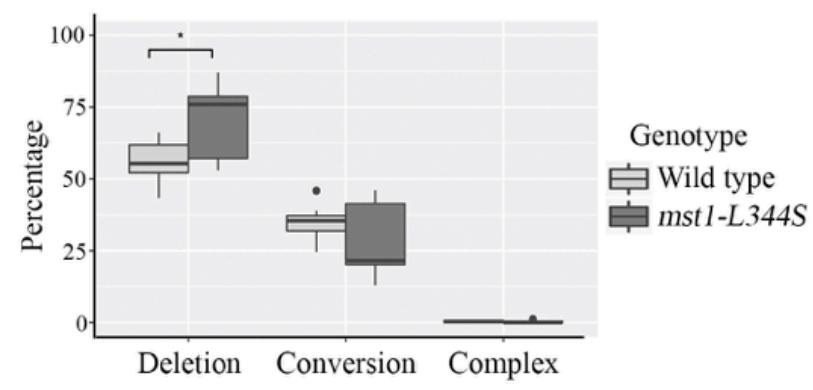

F
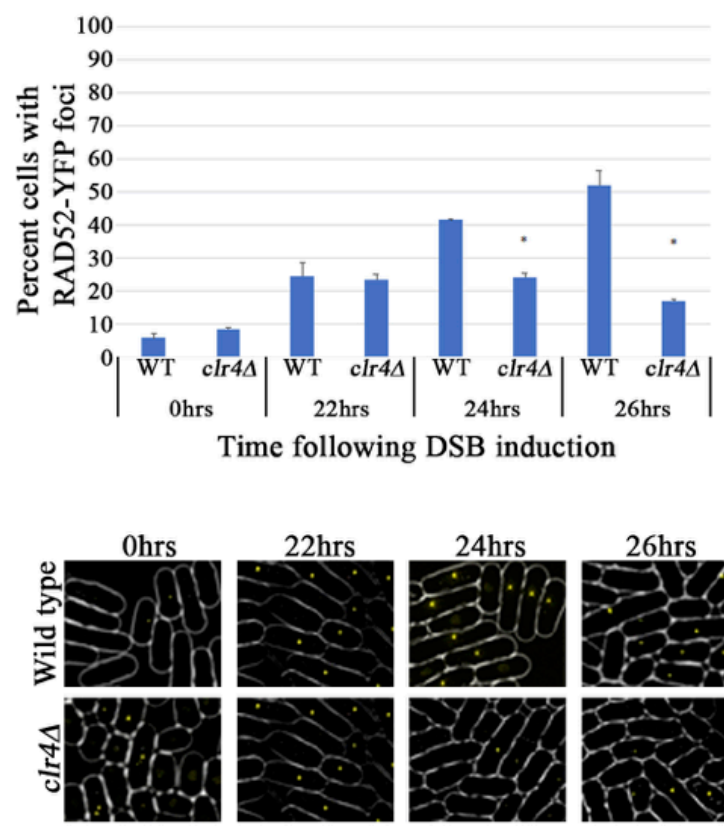

$26 \mathrm{hrs}$

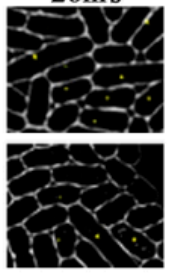


bioRxiv preprint doi: https://doi.org/10.1101/2020.06.03.132316; this version posted March 3, 2021. The copyright holder for this preprint (which was not certified by peer review) is the author/funder, who has granted bioRxiv a license to display the preprint in perpetuity. It is made available under aCC-BY-NC-ND 4.0 International license.

Figure 2. The mst1-L344S mutant affects recruitment of repair proteins.

A
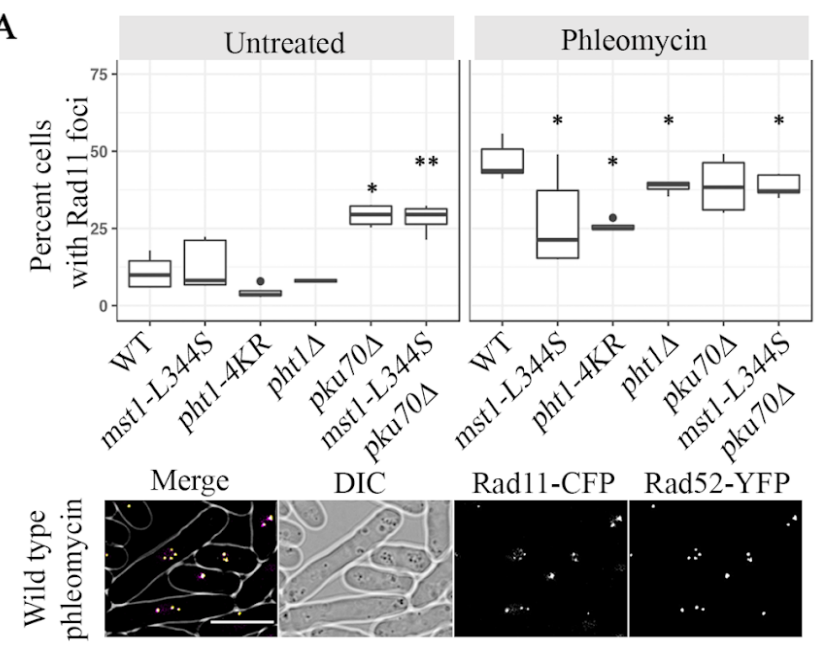

B
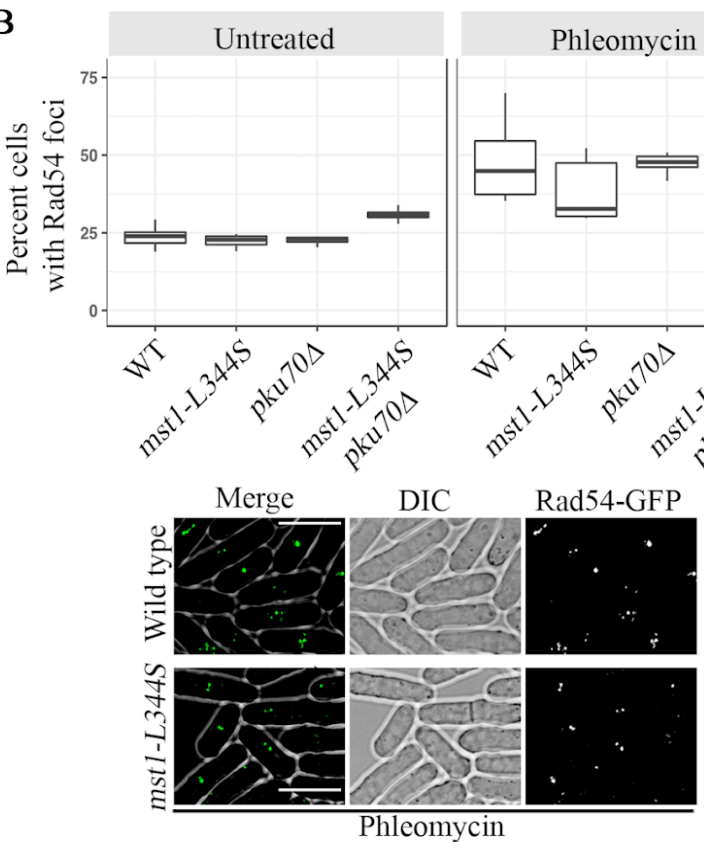

D

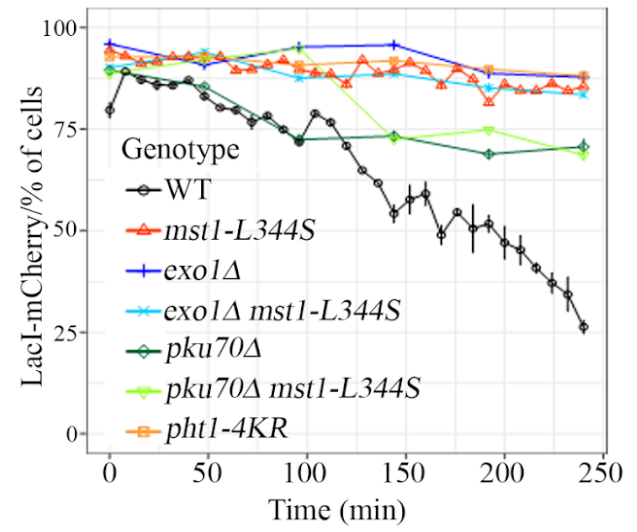

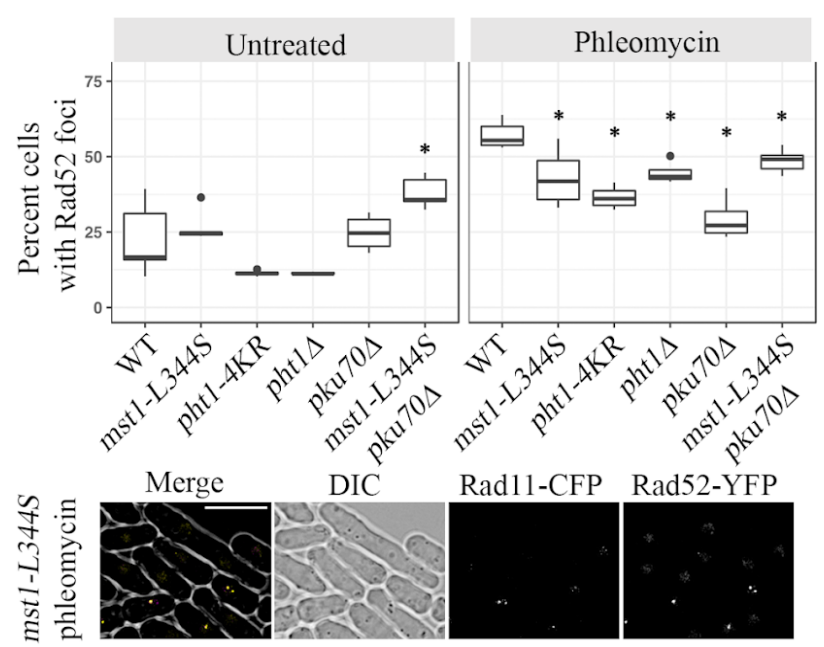

C

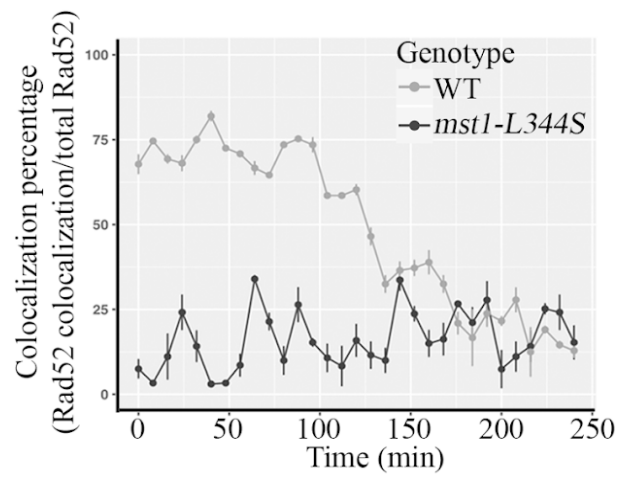

$160^{\prime}$

LacI-mCherry, Rad52-YFP
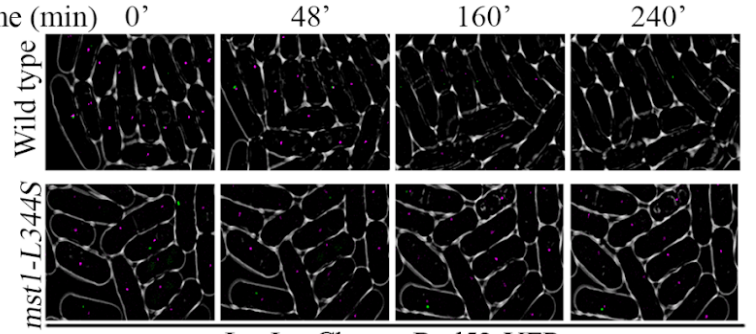

$240^{\prime}$ 
bioRxiv preprint doi: https://doi.org/10.1101/2020.06.03.132316; this version posted March 3, 2021. The copyright holder for this preprint (which was not certified by peer review) is the author/funder, who has granted bioRxiv a license to display the preprint in perpetuity. It is made available under aCC-BY-NC-ND 4.0 International license.

Figure 3. mst1-L344S mutants are sensitive to the DSB-inducing agent bleomycin.

A

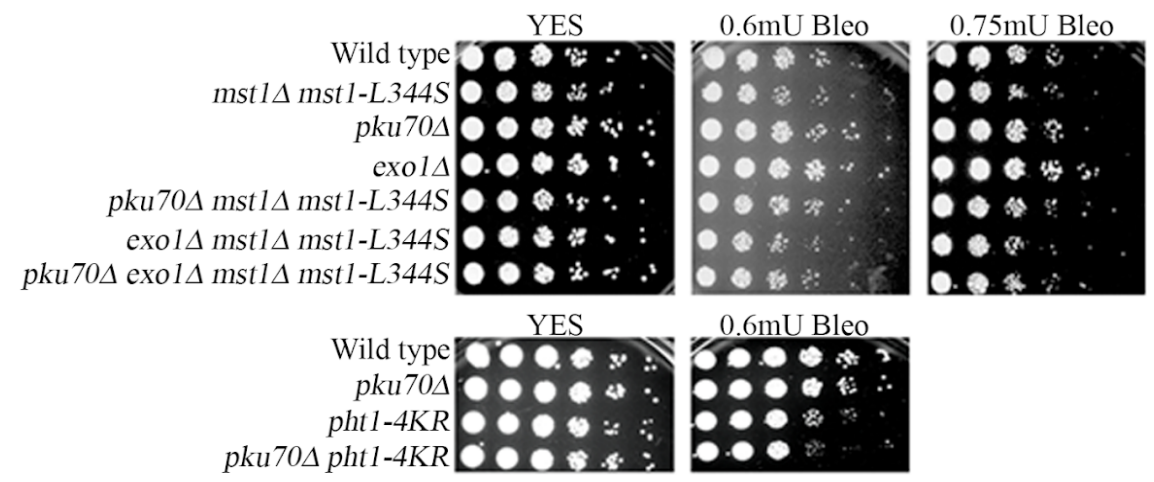


bioRxiv preprint doi: https://doi.org/10.1101/2020.06.03.132316: this version posted March 3 2021. The copyright holder for this preprin (which was not certified by peer review) is the author/funder, who has granted bioRxiv a license to display the preprint in perpetuity. It is made available under aCC-BY-NC-ND 4.0 International license.

Figure 4. Mst1 affects DNA lesion repair but does not affect checkpoint activation.

A

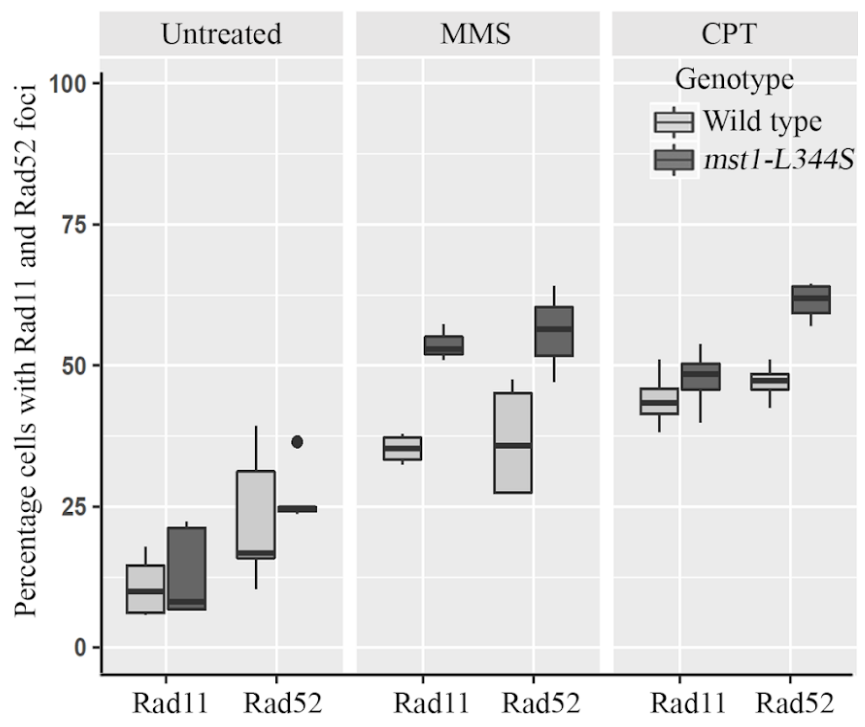

B Chk1-HA

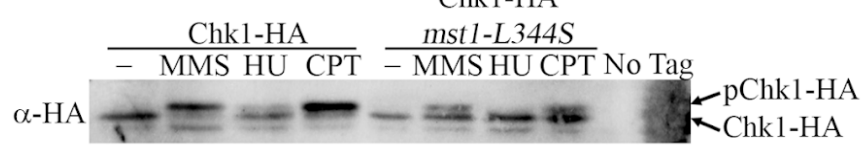

$\alpha-$ Tubulin

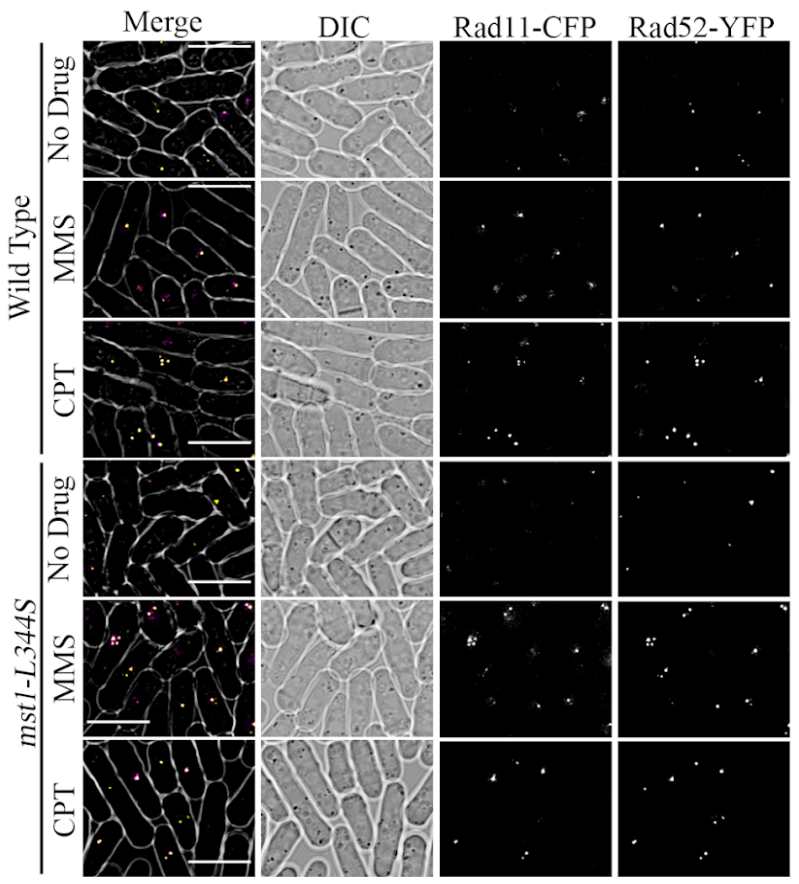

$\mathrm{C}$

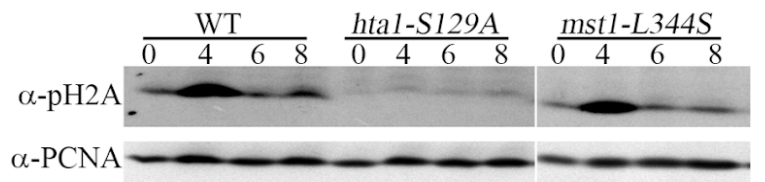


Figure 5. Model for the function of Mst1

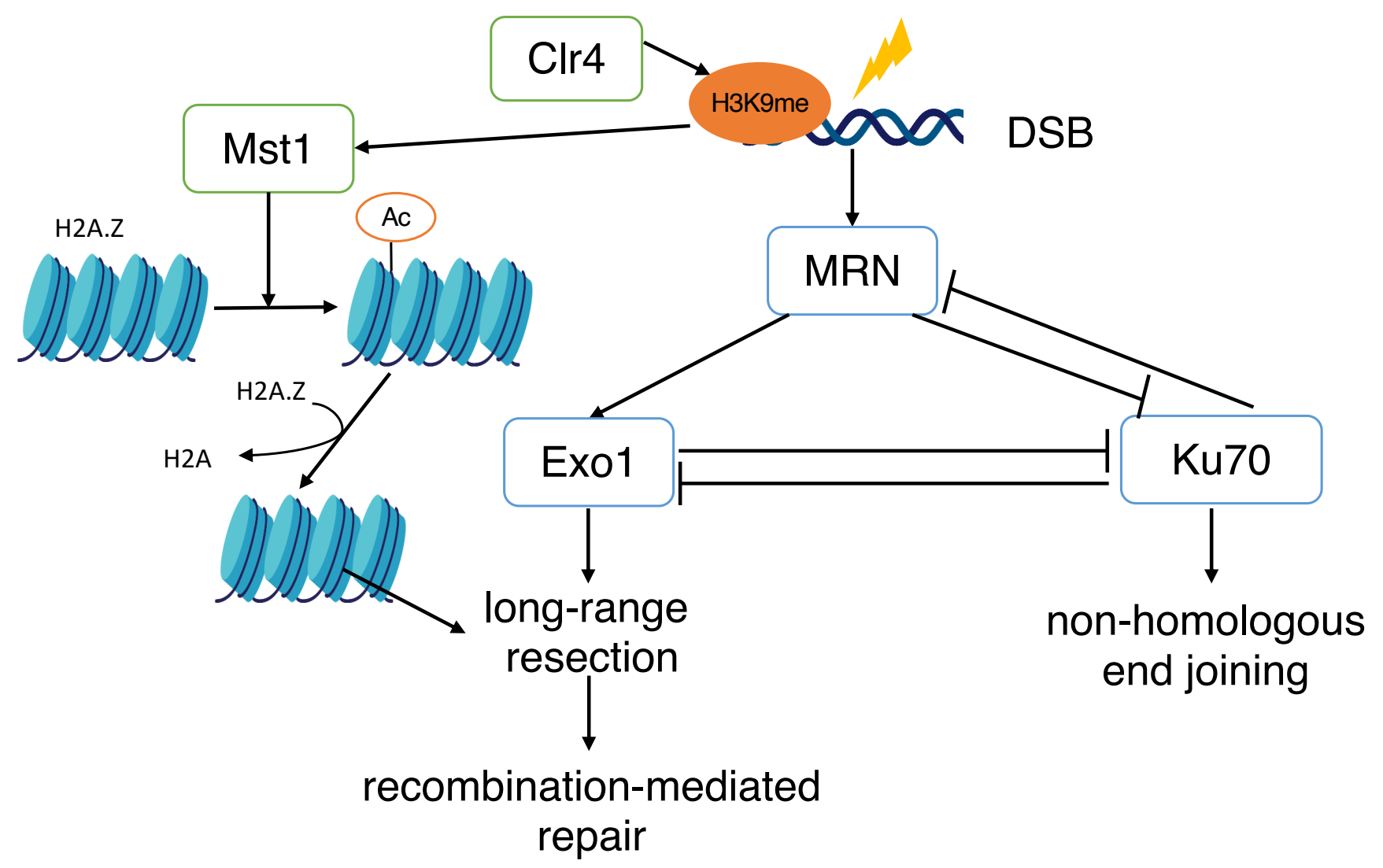


bioRxiv preprint doi: https://doi.org/10.1101/2020.06.03.132316; this version posted March 3, 2021. The copyright holder for this preprint (which was not certified by peer review) is the author/funder, who has granted bioRxiv a license to display the preprint in perpetuity. It is made available under aCC-BY-NC-ND 4.0 International license.

Supplementary Figure S1. The mst1-L344S mutants are sensitive to the bleomycin analog phelomycin.

\begin{tabular}{|c|c|c|}
\hline & YES & $3 \mu \mathrm{g} / \mathrm{mL}$ phleomycin \\
\hline Wild type & 10000 क t & 6009 \\
\hline & $0000 \%$ & 0 策 \\
\hline $\operatorname{rad} 52 \Delta$ & $10^{\circ} 0^{\circ} 0^{\circ} \mathrm{O}$ & \\
\hline t1-L344S & $5000 \%$ & 000 \\
\hline t1-L344 & 500003 & $000 \div$ \\
\hline mstl-L344S & $100000 x$ & 000 \\
\hline
\end{tabular}


bioRxiv preprint doi: https://doi.org/10.1101/2020.06.03.132316; this version posted March 3, 2021. The copyright holder for this preprin (which was not certified by peer review) is the author/funder, who has granted bioRxiv a license to display the preprint in perpetuity. It is made available under aCC-BY-NC-ND 4.0 International license.

Supplementary Figure S2. Examples of cell with RPA (Rad11), Rad52, and Rad54 foci after treatement with phleomycin.

A
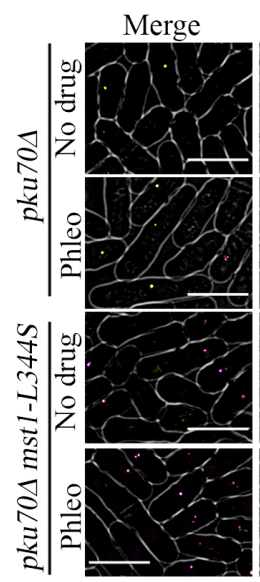

DIC

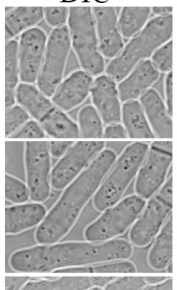

Rad11-CFP

Rad52 YFP

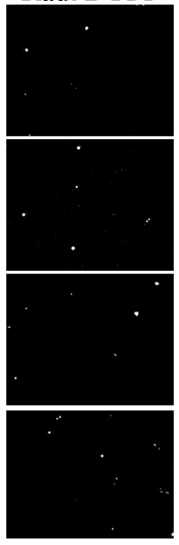

B

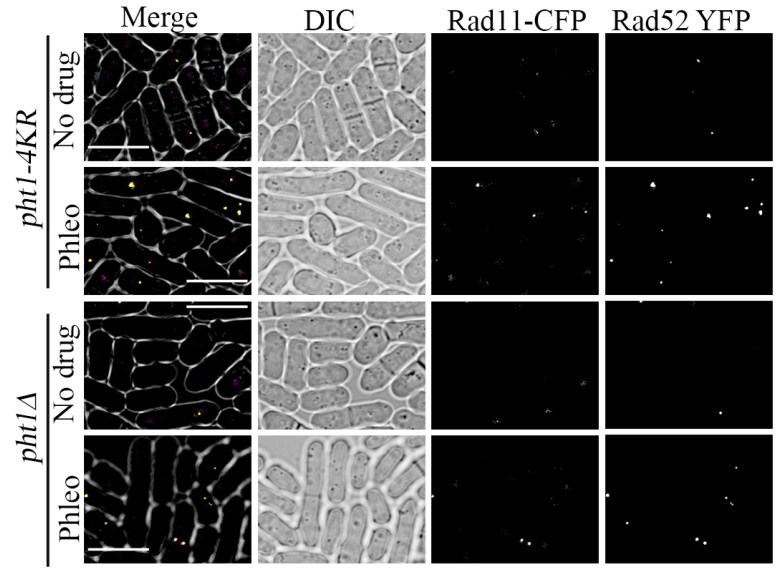

$\mathrm{C}$

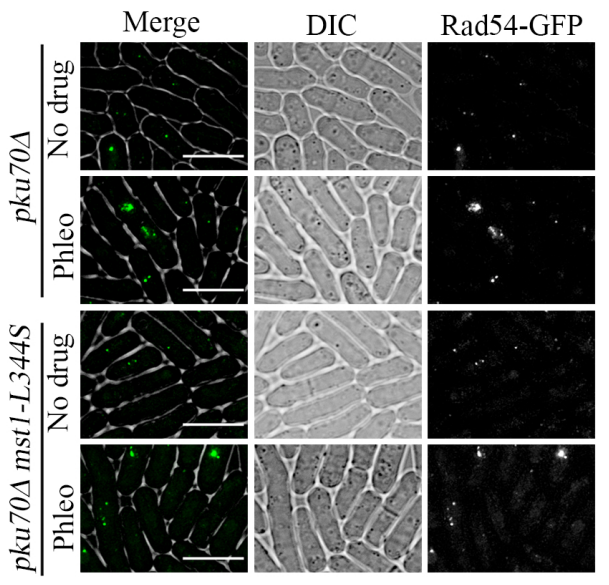


bioRxiv preprint doi: https://doi.org/10.1101/2020.06.03.132316; this version posted March 3, 2021. The copyright holder for this preprint (which was not certified by peer review) is the author/funder, who has granted bioRxiv a license to display the preprint in perpetuity. It is made available under aCC-BY-NC-ND 4.0 International license.

Supplementary Figure S3. pku70 $\Delta$ does not affect cell length at septation in mst1-L344S at $25^{\circ} \mathrm{C}$.

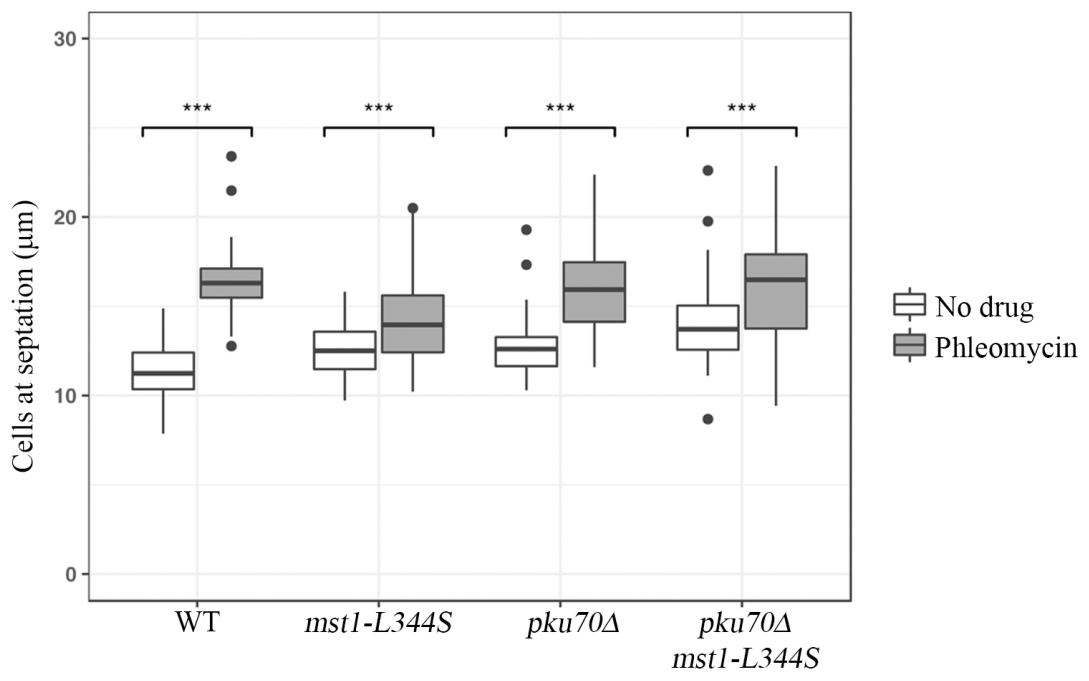


bioRxiv preprint doi: https://doi.org/10.1101/2020.06.03.132316; this version posted March 3, 2021. The copyright holder for this preprint (which was not certified by peer review) is the author/funder, who has granted bioRxiv a license to display the preprint in perpetuity. It is made available under aCC-BY-NC-ND 4.0 International license.

Supplementary Figure S4. mst1-L344S interacts genetically with genes in the checkpoint pathways.

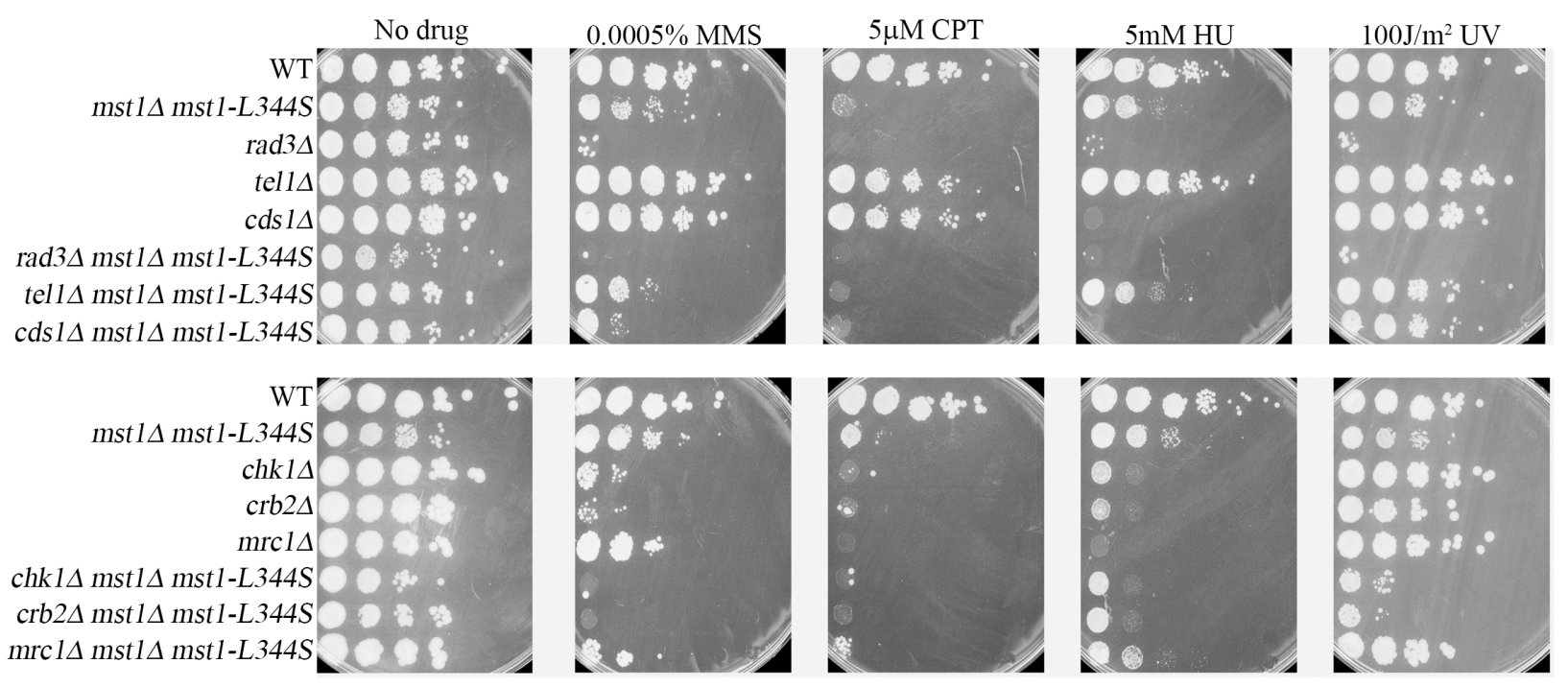


Supplementary Table S1. Median, first and third quartiles of cells with Rad11-CFP, Rad52-YFP and Rad54-GFP foci percentages.

\begin{tabular}{|c|c|c|c|}
\hline & \multicolumn{3}{|c|}{ Rad11 } \\
\hline & Median & 1st Quantile & 3rd Quantile \\
\hline WT Untreated & 9.9 & 6.1 & 14.51 \\
\hline WT Phleomycin & 43.72 & 42.98 & 50.7 \\
\hline mst1-L344S Untreated & 8.14 & 6.76 & 21.15 \\
\hline mst1-L344S Phleomycin & 21.3 & 15.38 & 37.29 \\
\hline phtI- $4 K R$ Untreated & 3.58 & 3.25 & 4.78 \\
\hline phtl-4KR Phleomycin & 24.96 & 24.76 & 25.95 \\
\hline pht $1 \Delta$ Untreated & 7.99 & 7.7 & 8.36 \\
\hline phtls Phleomycin & 39.2 & 37.75 & 39.86 \\
\hline pkai70s Untreated & 29.48 & 26.4 & 32.27 \\
\hline$p k a 70 \Delta \mathrm{Phleomycin}$ & 38.31 & 30.99 & 46.27 \\
\hline pkai70 mst1-L344S Untreated & 29.5 & 26.38 & 31.32 \\
\hline \multirow[t]{3}{*}{ pkai70s mst1-L344S Phleomycin } & 37.08 & 36.62 & 42.3 \\
\hline & \multicolumn{3}{|c|}{$\operatorname{Rad} 52$} \\
\hline & Median & 1st Quantile & 3rd Quantile \\
\hline WT Untreated & 16.67 & 15.85 & 31.17 \\
\hline WT Phleomycin & 55.4 & 53.77 & 60 \\
\hline mst1-L344S Untreated & 24.73 & 24.12 & 24.89 \\
\hline mst1-L344S Phleomycin & 41.85 & 35.76 & 24.89 \\
\hline pht $1-4 K R$ Untreated & 11.26 & 10.98 & 11.63 \\
\hline pht $1-4 K R$ Phleomycin & 36.05 & 33.84 & 38.7 \\
\hline pht $1 \Delta$ Untreated & 11.11 & 11.11 & 11.51 \\
\hline phtls Phleomycin & 43.42 & 42.53 & 45.59 \\
\hline pkai70s Untreated & 24.7 & 20.28 & 29.16 \\
\hline pka $i 0 \Delta$ Phleomycin & 27.19 & 24.71 & 31.83 \\
\hline pka $70 \Delta$ mstl-L344S Untreated & 35.75 & 35.2 & 42.32 \\
\hline \multirow[t]{3}{*}{ pkai70s mstl-L344S Phleomycin } & 49.09 & 46.02 & 50.4 \\
\hline & \multicolumn{3}{|c|}{$\operatorname{Rad54}$} \\
\hline & Median & 1st Quantile & 3rd Quantile \\
\hline WT Untreated & 23.91 & 21.72 & 25.22 \\
\hline WT Phleomycin & 44.91 & 37.34 & 54.55 \\
\hline mstI-L344S Untreated & 22.74 & 21.18 & 23.85 \\
\hline mst1-L344S Phleomycin & 32.7 & 30.28 & 47.48 \\
\hline pkai70s Untreated & 23.04 & 22.06 & 23.47 \\
\hline pka $70 \Delta$ Phleomycin & 47.78 & 46.09 & 49.55 \\
\hline pka $70 \Delta$ mstl-L344S Untreated & 30.74 & 29.99 & 31.6 \\
\hline pka 70s mst1-L344S Phleomycin & 40.97 & 40.04 & 43.37 \\
\hline
\end{tabular}


bioRxiv preprint doi: https://doi.org/10.1101/2020.06.03.132316; this version posted March 3,2021 . The copyright holder for this preprint (which was not certified by peer review) is the author/funder, who has granted bioRxiv a license to display the preprint in perpetuity. It is made available under aCC-BY-NC-ND 4.0 International license.

803 Supplementary Table S2. Strains used in this study.

\begin{tabular}{|c|c|c|}
\hline Strain & Genotype & Source \\
\hline FY254 & h-can1-1 leu1-32 ade6-M210 ura4-D18 & Our stock \\
\hline FY255 & $h+$ canl-1 leu1-32 ade6-M210 ura4-D18 & Our stock \\
\hline FY527 & h- his3-D1 ade6-M216 ura4-D18 leu1-32 & Our stock \\
\hline FY528 & $h+$ his3-D1 ade6-M210 ura4-D18 leu1-32 & Our stock \\
\hline FY421 & h-ade6-704 leu1-32 ura4-D18 $\Delta$ chk1::ura4 & Our stock \\
\hline FY4743 & h- rad11-Cerulean::hphMX rad22-YFP-natMX leu1-32 ade6-M210 ura4-D18 & Our stock \\
\hline FY8927 & $\begin{array}{l}\text { h90 mst1-L344S-5FLAG:hphMX6 rad11-Cerulean::hphMX rad22-YFP-natMX } \\
\text { leu1-32 ura4-D18 }\end{array}$ & This study \\
\hline FY1106 & $h+\Delta$ rad3::ura4+ ura4-D18 leu1-32 ade6-M210 & Our stock \\
\hline FY1204 & $h+\Delta$ rhp51::ura4+ade6-704 leu1-32 ura4-D18 & Our stock \\
\hline FY1353 & $h+$ leul-32 ura4-D18 his3-D1 ade6-M210 pku70::kanr & Our stock \\
\hline FY2396 & h- $\Delta m s t 1::$ ura $4+$ leu1::nmt-mst1L-S leu1+ ura4-D18 ade6-M210 & Our stock \\
\hline FY2449 & $h+\Delta m s t 1:: k a n M X 6$ leu1::nmt-mst1L-S-leu1+ ura4-D18 ade6-M210 & Our stock \\
\hline FY2450 & h- $\Delta m s t 1:: k a n M X 6$ leu1::nmt-mst1L-S-leu1+ ura4-D18 ade6-M210 & Our stock \\
\hline FY2504 & $\begin{array}{l}\text { h- } \Delta \text { rhp9::ura4+ (=crb2) mst1::kanMX6 leu1::nmt-mst1L-S-leu1+ ura4-D18 leu1- } \\
32 \text { ade6-M21? }\end{array}$ & This study \\
\hline FY2643 & $\begin{array}{l}\text { h- } \Delta \text { chk1::ura4+ } \Delta \text { mst1::kanMX6 leu1::nmt-mst1L-S-leu1+ ura4-D18 ade6-M210 } \\
\text { or } 704\end{array}$ & Our stock \\
\hline FY2725 & h- $\Delta$ pku70::kanr $\Delta m s t 1::$ ura4+ leu1::nmt-mst1L-S leu1+ ura4-D18 ade6-M210 & Our stock \\
\hline FY2726 & h- $\Delta$ pku70::kanr $\Delta m s t 1::$ ura $4+$ leu1::nmt-mst1L-S leu1+ ura4-D18 ade6-M210 & Our stock \\
\hline FY3135 & h-ade6-M210 leu1-32 ura4-D18 hip1::ura4+ & $\begin{array}{l}\text { Simon } \\
\text { Whitehall }\end{array}$ \\
\hline FY3151 & h- $\Delta m r c 1::$ ura4+ ura4-D18 leu1-32 his7-366 & Our stock \\
\hline FY3439 & h-ura4-D18 leu1-32 ade6-M216 his3-D1 $\Delta r h p 9:: u r a 4+\quad(=c r b 2)$ & Our stock \\
\hline FY3562 & $h+\Delta m s t 1:: k a n M X 6$ leu1::nmt-mst1L-S-leu1+ ade6-M210 ura4-D18 $\Delta$ hip1::ura4+ & Our stock \\
\hline FY3857 & $h+\Delta$ rhp $51::$ ura4 $4+\Delta m s t 1:: k a n M X 6$ leu1::nmt-mst1L-S leu1+ura4-D18 leu1-32 & This study \\
\hline FY3884 & h- exo1::ura4 ura4-D18 & $\begin{array}{l}\text { Mathew } \\
\text { O'Connell }\end{array}$ \\
\hline FY4713 & $\begin{array}{l}\text { h- } \Delta m s t 1:: k a n M X 6 \Delta m r c 1:: u r a 4+\text { leu1::nmt-mst1L-S-leu1+ ura4-D18 ade6-M210 } \\
\text { leu1-32 }\end{array}$ & This study \\
\hline FY5304 & $h+\Delta m s t 1:: k a n M X 6$ leu1::nmt-mst1L-S-leu1+exo1::ura4+ ura4-D18 leu1-32 & This study \\
\hline FY5311 & h+ pht1-4KtoR-3HA-KanMX6 ura4-D18 leu1-32 ade6-M216 his3-D1 & $\begin{array}{l}\text { Michael } \\
\text { Keogh }\end{array}$ \\
\hline FY6024 & $h+$ mst1-L344S-5FLAG:hphMX6 leul-32 ura4-D18 & $\begin{array}{l}\text { Eishi } \\
\text { Noguchi }\end{array}$ \\
\hline FY6229 & $\begin{array}{l}\text { h- leu1-32 ura4-D18 ade6-M26 int::pUC8/ura4+/MATa/ade6-L469 his3-D1 ade6- } \\
\text { M216 }\end{array}$ & Our stock \\
\hline FY6632 & h-pku70::kanr his3-D1 ura4-D18 leu1-32 ade6-M216 & Our stock \\
\hline FY8929 & $\begin{array}{l}\text { h- mst1-L344S-5FLAG:hphMX6 leu1-32 ura4-D18 ade6-M26 } \\
\text { int::pUC8/ura4+/MATa/ade6-L469 his3-D1 ade6-M216 }\end{array}$ & This study \\
\hline FY9153 & $\begin{array}{l}\text { h+ pht1::ura4 rad11-Cerulean::hphMX rad22-YFP-natMX leu1-32 ade6-M210 } \\
\text { ura4-D18 }\end{array}$ & Our stock \\
\hline FY9154 & $\begin{array}{l}h+\text { pht1-4KtoR-3HA-KanMX6 rad11-Cerulean:: hphMX rad22-YFP-natMX ura4- } \\
\text { D18 leu1-32 ade6-M216/210 his3-D1? }\end{array}$ & This study \\
\hline
\end{tabular}


bioRxiv preprint doi: https://doi.org/10.1101/2020.06.03.132316; this version posted March 3,2021 . The copyright holder for this preprint (which was not certified by peer review) is the author/funder, who has granted bioRxiv a license to display the preprint in perpetuity. It is made available under aCC-BY-NC-ND 4.0 International license.

\begin{tabular}{|c|c|c|}
\hline FY9338 & $\begin{array}{l}\text { h- mst1-L344S-5FLAG:hphMX6 pku70::kanr rad11-Cerulean::hphMX rad22- } \\
\text { YFP-natMX leu1-32 ura4-D18 his3-D1? ade6-M210 }\end{array}$ & This study \\
\hline FY9352 & $\begin{array}{l}\text { h- pku70::kanr rad11-Cerulean::hphMX rad22-YFP-natMX leu1-32 ura4-D18 } \\
\text { his3-D1? ade6-M210 }\end{array}$ & This study \\
\hline FY8989 & h- rad54-GFP:hphMX6 & $\begin{array}{l}\text { Takuro } \\
\text { Nakagawa }\end{array}$ \\
\hline FY9023 & h- mst1-L344S-5FLAG:hphMX6 rad54-GFP:hphMX6 leu1-32? ura4-D18? & This study \\
\hline FY9340 & h- pku70::kanr rad54-GFP:hphMX6 leu1-32? his3-D1? ade6-M210? & This study \\
\hline FY9353 & $\begin{array}{l}\text { h- mst1-L344S-5FLAG:hphMX6 pku70::kanr rad54-GFP:hphMX6 leu1-32? his3- } \\
\text { D1? ade6-M210? }\end{array}$ & This study \\
\hline FY7479 & $\begin{array}{l}\text { h-arg3::HOsite-natMX ars } 1:: p 41 \text { nmt1-HO(his3+) lys } 1-131:: \text { pdis1-mCherry- } \\
\text { lacI(lys1+) erg7ter::lacO(ura4+) rad52-tandemCFP::kanMX leu1-32 his3-D1 } \\
\text { ura4-294 }\end{array}$ & Li-Lin Du \\
\hline FY8992 & $\begin{array}{l}\text { h- mst1-L344S-5FLAG:hphMX6 arg3::HOsite-natMX ars1::p41nmt1-HO(his3+) } \\
\text { lys 1-131::pdis1-mCherry-lacI(lys1+) erg7ter::lacO(ura4+) rad52- } \\
\text { tandemCFP::kanMX leu1-32 his3-D1 ura4-294/D18? }\end{array}$ & This study \\
\hline FY4620 & h-chk1HA(ep) cds1-myc::KanMX ade6-M216 ura4-D18 leu1-32 & Our stock \\
\hline FY9495 & 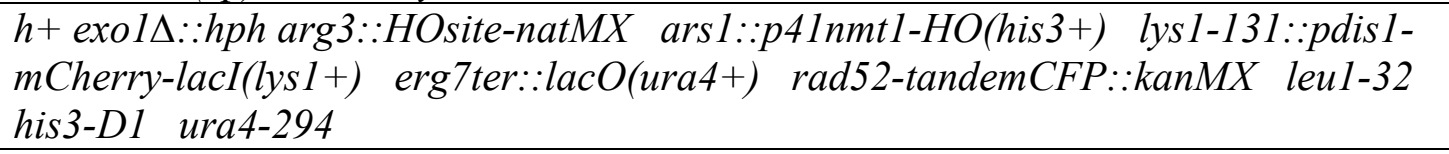 & This study \\
\hline FY9499 & $\begin{array}{l}\text { h- pku70::kanr arg3::HOsite-natMX ars } 1:: p 41 \text { nmt1-HO(his3+) lys } 1-131:: p d i s 1- \\
\text { mCherry-lacI(lys } 1+) \text { erg7ter }:: \text { lacO(ura4+) rad52-tandemCFP }:: k a n M X \text { leu1-32 } \\
\text { his3-D1 ura4-294/D18 ade6-M210? }\end{array}$ & This study \\
\hline FY9502 & $\begin{array}{l}\text { h-pht1-4KtoR-3HA-KanMX6 arg3::HOsite-natMX ars1::p4lnmt1-HO(his3+) } \\
\text { lys } 1-131:: \text { pdis } 1-m \text { Cherry-lacI(lys } 1+) \text { erg7ter::lacO(ura4+) rad52- } \\
\text { tandemCFP::kanMX leu1-32 his3-D1 ura4-294/D18? }\end{array}$ & This study \\
\hline FY9514 & 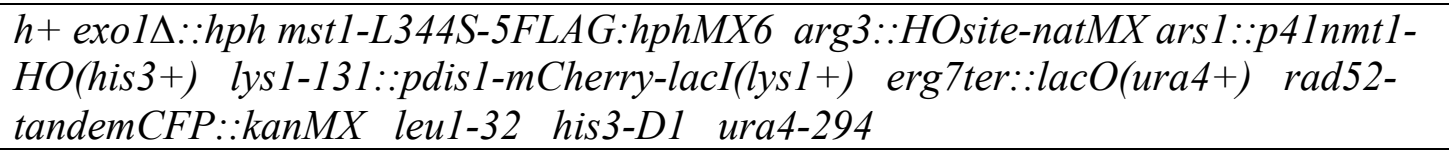 & This study \\
\hline FY9542 & $\begin{array}{l}\text { h-pku70::kanr mst1-L344S-5FLAG:hphMX6 arg3::HOsite-natMX ars1::p41nmt1- } \\
\text { HO(his3+) lys1-131::pdis1-mCherry-lacI(lys1+) erg7ter::lacO(ura4+) rad52- } \\
\text { tandemCFP::kanMX leu1-32 his3-D1 ura4-294/D18 ade6-M210? }\end{array}$ & This study \\
\hline FY5083 & $\begin{array}{l}\text { h- } \Delta m s t 1:: k a n M X 6 \text { leu1::nmt-mst1L-S-leu1+ chk1HA(ep) cds1-myc::KanMX } \\
\text { ura4-D18 ade6-M210/216? }\end{array}$ & This study \\
\hline FY3397 & $\begin{array}{l}\text { h- leu1-32 ura4-D18 ade6-M210 his3-D1 hta1-S129A:ura4+ hta2- } \\
\text { S128A:his3+ }\end{array}$ & $\begin{array}{l}\text { Takuro } \\
\text { Nakagawa }\end{array}$ \\
\hline FY5548 & $\begin{array}{l}\text { h- ura4-D18 leu1-32 his3-D1 ade6-M210 mst1::[mst1-V5 leu1+] rad22- } \\
\text { YFP::hphMX arg3::HOsite(KanMX4) ars } 1:: \text { nmt41- } \\
\text { HOendonuclease:ampR:his3+:ars1 }\end{array}$ & Our stock \\
\hline FY9561 & $\begin{array}{l}\text { h- clr4::kanMX6-Bioneer mst } 1::[m s t 1-V 5 \text { leu1+] rad22-YFP::hphMX } \\
\text { arg3::HOsite(KanMX4) ars } 1:: n m t 41-H O e n d o n u c l e a s e: \text { ampR:his3+:ars } 1 \text { his3-D1 } \\
\text { ura4-D18 leu1-32 ade6-M210 }\end{array}$ & This study \\
\hline
\end{tabular}

